\title{
Review Article \\ Electrospinning of Nanofibers and Their Applications for Energy Devices
}

\author{
Xiaomin Shi, ${ }^{1}$ Weiping Zhou, ${ }^{1}$ Delong Ma, ${ }^{1}$ Qian Ma, ${ }^{2}$ Denzel Bridges, ${ }^{2}$ \\ Ying $\mathrm{Ma}^{1}{ }^{1}$ and Anming $\mathrm{Hu}^{1,2}$ \\ ${ }^{1}$ Institute of Laser Engineering, Beijing University of Technology, 100 Pingle Yuan, Chaoyang District, Beijing 100241, China \\ ${ }^{2}$ Department of Mechanical, Aerospace and Biomedical Engineering, University of Tennessee, 1512 Middle Drive, Knoxville, \\ TN 37996, USA
}

Correspondence should be addressed to Anming Hu; anminghu@bjut.edu.cn

Received 11 January 2015; Revised 21 April 2015; Accepted 29 April 2015

Academic Editor: Bala Vaidhyanathan

Copyright (C) 2015 Xiaomin Shi et al. This is an open access article distributed under the Creative Commons Attribution License, which permits unrestricted use, distribution, and reproduction in any medium, provided the original work is properly cited.

\begin{abstract}
With the depletion of fossil fuels and the increasing demand of energy for economic development, it is urgent to develop renewable energy technologies to sustain the economic growth. Electrospinning is a versatile and efficient fabrication method for onedimensional (1D) nanostructured fibers of metals, metal oxides, hydrocarbons, composites, and so forth. The resulting nanofibers (NFs) with controllable diameters ranging from nanometer to micrometer scale possess unique properties such as a high surfacearea-to-volume and aspect ratio, low density, and high pore volume. These properties make 1D nanomaterials more advantageous than conventional materials in energy harvesting, conversion, and storage devices. In this review, the key parameters for espinning are discussed and the properties of electrospun NFs and applications in solar cells, fuel cells, nanogenerators, hydrogen energy harvesting and storage, lithium-ion batteries, and supercapacitors are reviewed. The advantages and disadvantages of electrospinning and an outlook on the possible future directions are also discussed.
\end{abstract}

\section{Introduction}

The human society is facing tremendous challenges with respect to depleting fossil energy and increasing energy demands. In order to solve these issues, the construction of efficient and clean energy conversion and storage devices, such as wind turbines, photovoltaic cells, and lithium-ion (secondary) battery, is essential. One-dimensional (1D) nanostructured materials such as nanofibers (NFs), nanowires (NWs) [1], nanotubes (NTs) [2], and nanorods (NRs) [3] have attracted extensive attention due to their unique physical and chemical characteristics. Among these 1D nanostructured materials, continuous NFs have been the focus of studies because of their unique properties compared to other nanostructured materials in the application of energy devices. Until now, numerous methods such as template-assisted synthesis [4], chemical vapor deposition (CVD) [5], self-assembly [6], wet chemical synthesis [7], and electrospinning have been applied to the preparation for nanofibrous materials.
Compared to other methods, electrospinning has the merits of simplicity, high efficiency, low cost, and high reproducibility. Electrospinning was first developed as a patent to produce continuous fibers in 1934 [8]. Since then, much attention has been focusing on this technique and its applications (as shown in Figure 1). As a versatile method, electrospinning can be applied to the fabrication of one-dimensional (1D) nanomaterials of polymers, inorganic materials, and composites with diameters ranging from tens of nanometers to several micrometers. Particularly, compared to $1 \mathrm{D}$ materials synthesized with other methods, the NFs prepared by electrospinning have larger specific surface areas, higher aspect ratio, and better pore interconnectivity, which are favorable for energy conversion and storage. In addition, electrospun NFs with various morphologies and structures such as coreshell [9], hollow [10], yarn [11], and porous [12] structures can be obtained by modifying process parameters including applied voltage, feed rate, collector type, tip-to-collector distance, nozzle design, and calcination treatment. In this 


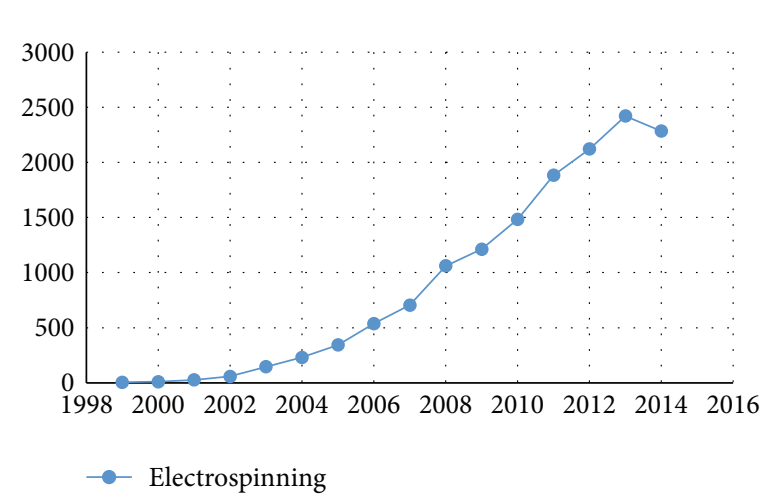

(a)

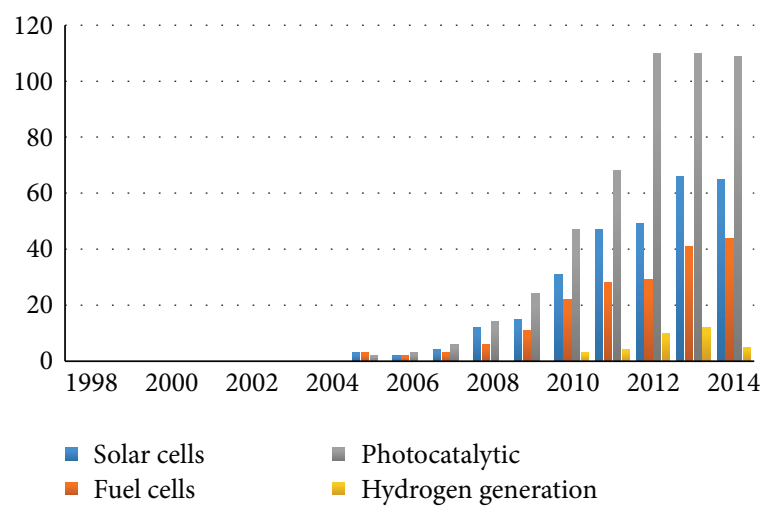

(b)

FIGURE 1: (a) The number of research publications produced between 1999 and 2014 using electrospinning and (b) research articles published using electrospun NFs in different energy-related areas between 1998 and 2014.

review, the fundamentals and properties of electrospun NFs are presented and applications in solar cells, fuel cells, nanogenerators, hydrogen energy harvesting and storage, lithiumion batteries, and supercapacitors are discussed. The advantages and disadvantages of electrospinning and an outlook on the possible future directions are also provided. Figure 1 shows the increasing number of publications relevant to electrospinning since 1999 and research articles of electrospun NFs in different energy-related domains between 1998 and 2014. It is obvious that there is significant growth of the energy-relative application research activities.

\section{Fundamentals of Electrospun Nanofibers}

2.1. Working Principles of Electrospinning. Electrospinning produces fibers with diameters ranging from nanometer to micrometer scale when the electrostatic force is applied on solutions or melts. A general electrospinning setup consists of three primary components as shown in Figure 2: a high voltage power supply (usually in the $\mathrm{kV}$ range), a syringe with a metallic needle, and a grounded collector (solid substrate or liquid media). In a typical electrospinning process, high voltage is applied on solutions or melts. Subsequently, a pendant droplet forms. When the electrostatic repulsion starts to overcome the surface tension of the fluid, the pendant droplet will deform into a conical droplet known as the Taylor cone at the tip of the needle. As the electrostatic force overcomes the surface tension of the conical droplet, a fine, charged jet of polymer solution is ejected from the tip of the needle. The interaction between the electric field and the surface tension of the fluid stretches the jet stream and makes it undergo a whipping motion leading to the evaporation of the solvent. This causes the jet stream to be continuously elongated as a long and thin filament and then this filament solidifies and is eventually deposited onto a grounded collector, resulting in the formation of a uniform fiber.

2.2. Orientation and Hierarchical Structures of NFs. NFs with different orientation and hierarchical structures can be produced by electrospinning. The orientation of NFs includes random and aligned structures as shown in Figure 3. In

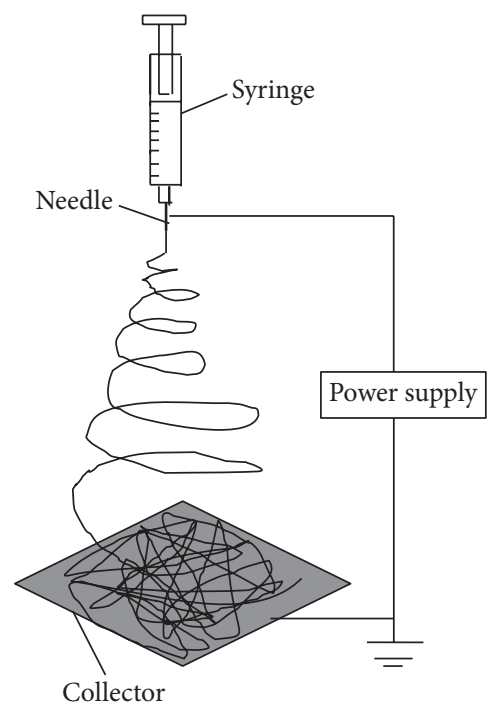

FIGURE 2: Schematic of a laboratory-scale electrospinning setup.

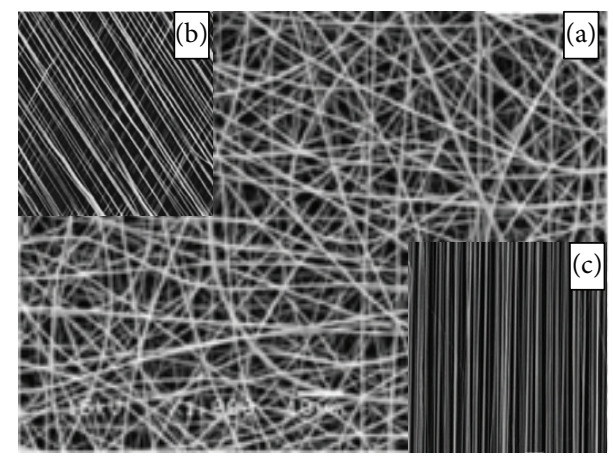

FIGURE 3: Scanning electron micrographs of electrospun (a) random NFs, (b) aligned fibers at an angle, and (c) aligned fibers (adapted from [21]).

particular, the well-aligned and highly ordered NFs are often required for energy devices. It is worth noting that the fiber collectors play a crucial role in obtaining aligned orientation. In the past decades, many progresses have been achieved 


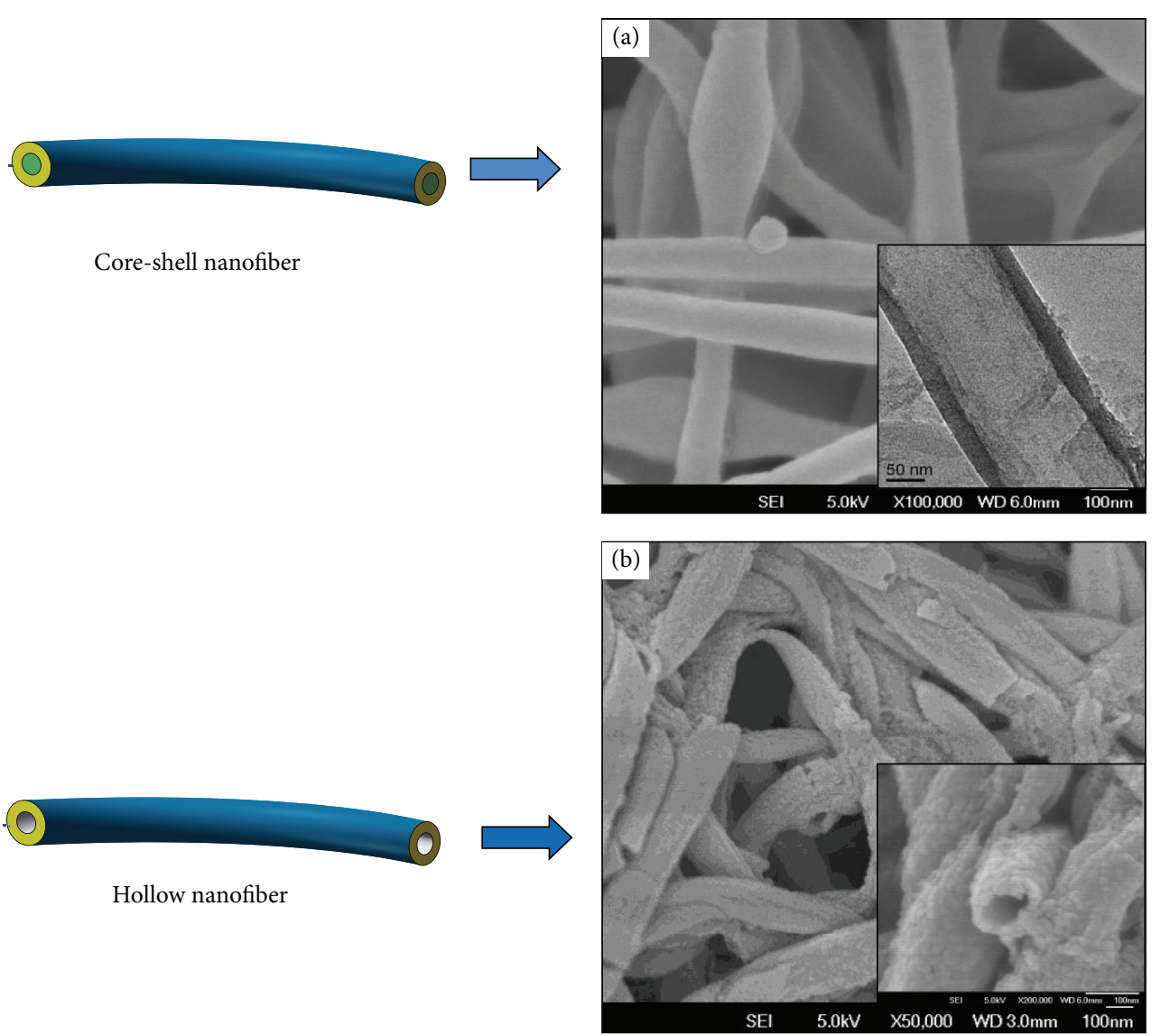

FIGURE 4: Schematic illustration (left side) and SEM of electrospun core-shell NFs and hollow NFs (right side) (adapted from [22]).

in enhancing alignment of electrospun NFs by using special designed collectors, such as rotating drum [13], metal frame [14], or two conductive substrates separated by a gap [15]. In addition, Teo et al. developed a liquid system combined with a rotating mandrel where continuous yarn was made from electrospun fibers [11].

In recent years, hierarchical nanostructured materials have attracted notable attention and have been found to have fascinating applications in dye-sensitized solar cells (DSSCs), hydrogen generation, photocatalysts, fuel cells, lithium-ion batteries (LIBs), biomedicine, and environmental remediation due to their unique properties $[16,17]$. Hierarchical electrospun NFs structures include core-shell, hollow (as shown in Figure 4), and porous structures. Besides, many studies on the manufacturing methods of hierarchical structures of NFs from different materials have been reported $[18,19]$. Briefly, the core-shell fibers can be formed by coelectrospinning using a spinneret with two coaxial capillaries where a polymer solution (shell) and a nonpolymer solution (core) or two different polymer solutions (core-shell) can be utilized as precursor solutions and cospun. In such a spinning process, the inner and outer precursor solutions reach the nozzle through their respective capillaries and form composite droplets. Driven by electrostatic repulsions between the surface charges, the shell liquid of the composite droplets was elongated thereby generating viscous stress. Then this viscous stress was transferred to the core layer and the core liquid was then rapidly stretched. A composite jet is thus formed [20]. Core-shell electrospun NFs were obtained after further stretching and solidifying the composite jet. Such core-shell NFs can be used to obtain hollow structured NFs after going through posttreatment like removal of polymer core (usually by solvent extraction or calcination).

\subsection{Near-Field Electrospinning and Electrohydrodynamic Jet} Printing. Near-field electrospinning (NFES) has been developed as a process of direct-written nanostructure or orderly nanoarrays for a variety of nanofibers in a controllable and continuous manner. The feature of NFES is that a shorter electrode-to-collector distance ranging from $500 \mu \mathrm{m}$ to $3 \mathrm{~mm}$ is to utilize the stable region of the electrospun jet close to the needle and a reduced applied voltage commonly $100 \mathrm{~V} \sim$ $600 \mathrm{~V}$ (dependent on the needle-to-substrate gap) is used to activate the process [23]. Compared with conventional electrospinning (far-field electrospinning), NFES is superior in two aspects. One is that it can realize the positioning of individual nanofibers with high precision by shortening the needle-to-collector distance. The other is that it can also enable an improved control of fiber morphology, which is essential for the exploitation of single active fibers for photonic or sensing applications [24]. Based on the above merits, so far, polymers like polyethylene oxide (PEO) $[25,26]$, 


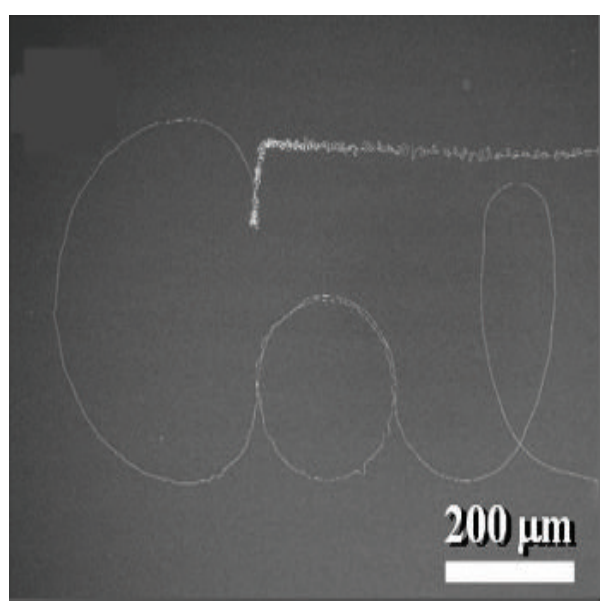

(a)

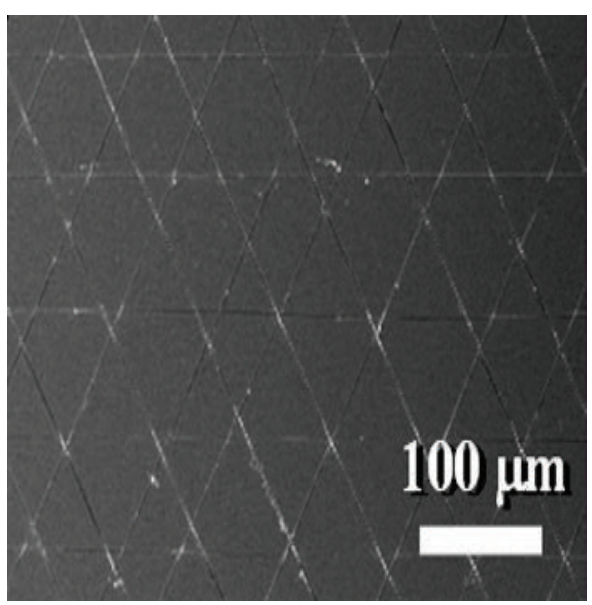

(b)

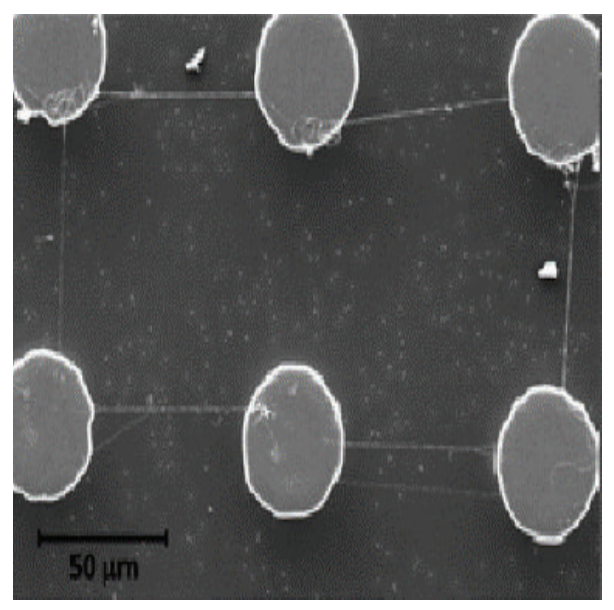

(c)

FIGURE 5: Scanning electron micrographs of NFES NFs. (a) The three-character Cal is drawn on a silicon chip by a programmable $x-y$ stage (reproduced from [25]). (b) A triangular pattern is formed by single continuous nanofiber deposited on a silicon chip for 15 min (reproduced from [25]). (c) Six carbon posts connected to each other by nanofibers obtained by NFES with 2 wt\% PEO polymer at $300 \mathrm{~V}$ (reproduced from [26]).

polycaprolactone [27], and composite (PEO/carbon NTs) [28] nanofibers have been successfully assembled in twodimensional even complex three-dimensional patterns such as character "Cal," triangular pattern, and six carbon posts connected by nanofibers fabricated with NFES (as shown in Figure 5). Such patterns can be achieved by using an $x$ $y$ stage. What is more, the well-aligned light-emitting conjugated polymer nanofibers have also been obtained via NFES, which is difficult to be synthesized with far-field electrospinning due to its incapacity for high spatial control, indicating the possibility of precise positioning and integration of conjugated polymer fibers into light-emitting devices [24]. Similar to the conventional electrospinning process, the diameter of nanofibers could be varied by adjusting various process parameters. However, contrary to conventional electrospinning, it has been found that higher voltage would result in fibers with larger diameters in NFES. This is because in NFES the initial polymer jet diameter instead of bending instability determines the final nanofiber diameter.
In addition to NFES, electrohydrodynamic (EHD) jet printing is another technology that can be utilized to directly write structures in two or three dimensions [29]. In the process of EHD jet printing, an electric potential lower than that used in NFES was applied between the nozzle and the substrate; thus a pulsating mode rather than a stable jet mode which was used in electrospinning occurred. Such a pulsating mode, also called nanodripping different from another pulsating-EHD jet printing mode in which the duration of the pulse determines the volume of the droplet and therefore the feature size on the substrate [30-32], can result in the ejection of single nanodroplet composed of nanoparticles from the apex of a liquid meniscus. After droplet impact and solvent vaporization, nanoparticles are uniformly distributed and their lateral size is equal to that of a single nanodroplet. Then the electric field will be applied again to guide the second droplet to locate in exactly the same spot and the schematic of EHD printing process is displayed as shown in Figure 6. It is worth noting that droplet diameter decreases 


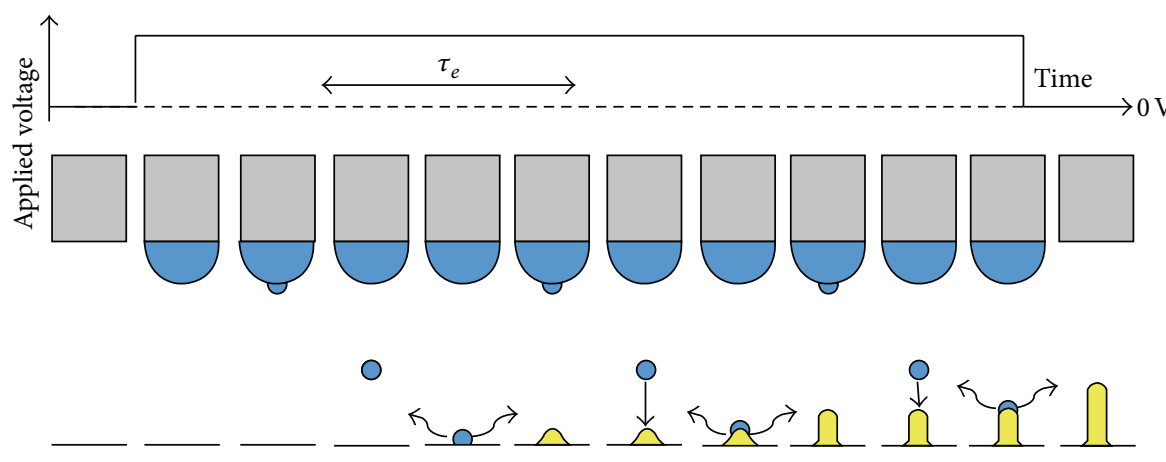

(a)

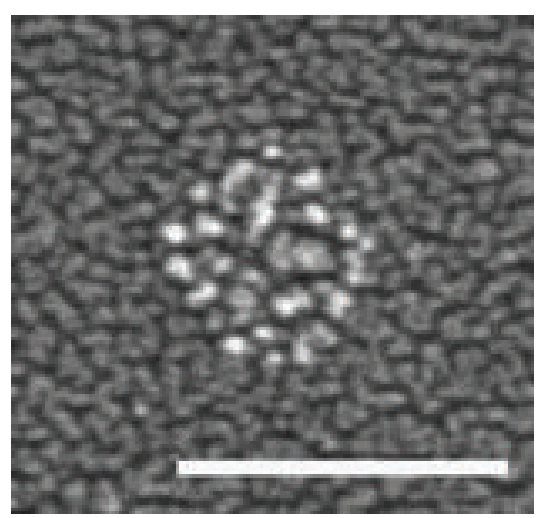

(b)

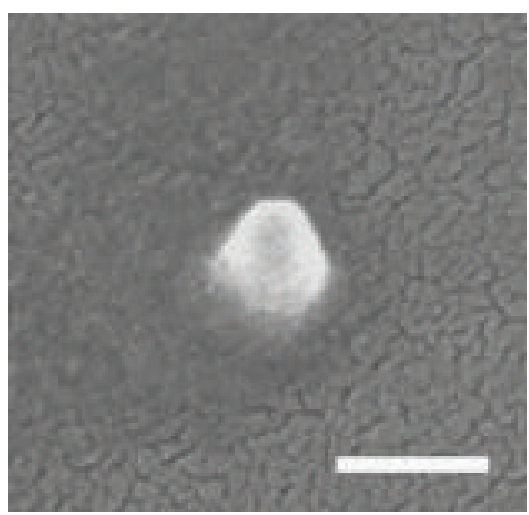

(c)

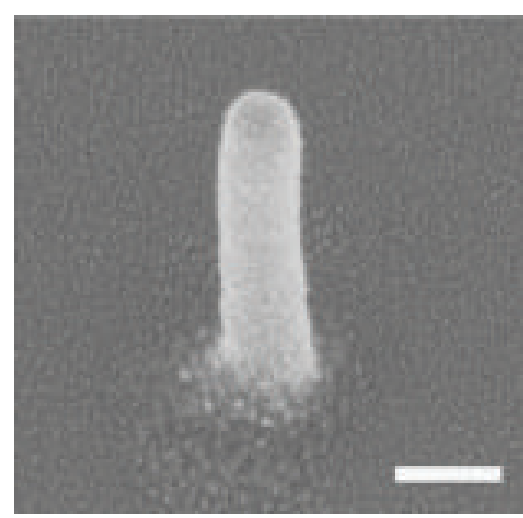

(d)

FIGURE 6: Schematic of EHD printing process. (a) Growth of a liquid meniscus and subsequent ejection of ink nanodroplets from its apex on application of a DC voltage. During DC on-time, droplets are ejected at a homogeneous period $\tau_{e}$ and, once impacted, are vaporized (represented by wavy arrows) in the course of $\tau_{e}$. After periodic repetition of this event (for illustration convenience merged into one cycle), a sharp structure consisting of a multitude of formerly dispersed nanoparticles rises from the substrate, attracting approaching charged droplets by EnA (straight arrows). The growth process is further illustrated with SEM micrographs (150 nm scale bar) of (b) the deposition pattern of a single nanodroplet and that of (c) actual nanopillar. (d) The deposition pattern of actual nanopillar with a $50 \mathrm{~nm}$ diameter and $850 \mathrm{~nm}$ height composed of gold nanoparticles (reproduced from [33]).

with the increase of applied voltage. However, when the applied voltage increases to a certain value, the droplet diameter will not vary with further enhancement of applied voltage. Compared with NFES, it is more difficult to obtain aligning continual patterns by EHD jet printing; however, it is still an attractive method to manufacture nanostructures that do not need essential requirement for alignment on a large scale [29].

2.4. Critical Parameters of Electrospinning. The characteristics of electrospun nanofibers depend on a number of parameters. These parameters are commonly divided into three categories: solution parameters (such as solution concentration and/or viscosity, solution surface tension, and solution conductivity), process parameters (such as feed rate, applied voltage, and tip to collector distance), and ambient conditions (like ambient temperature and humidity) [3436]. The following will discuss the influential parameters on morphology and diameter of fibers in the process of electrospinning.

2.4.1. Solution Concentration. Solution concentration is one of the factors that determine the diameter of fibers. It has been found that fibers with a smaller diameter can be obtained by reducing the concentration of the polymer solution. However, when the solution concentration is decreased to the entanglement concentration (Ce), beaded fibers are produced [37]. Once below Ce only droplets containing the polymer solution are collected because of no entanglements formation. An increase in concentration above Ce prevents the formation of beaded fibers and when the increase is up to $2-2.5$ times Ce smooth fibers are obtained $[37,38]$. When the concentration is too high, helix-shaped microribbons are formed [39].

2.4.2. Feed Rate. The feed rate of the solution is a crucial factor that influences the diameter and morphology of fibers in the electrospinning process. As the feed rate of the solution increases, the charge density will decrease. A high charge density may lead to the electrospinning jet undergoing secondary bending instabilities, which contributes to the formation of fibers with smaller diameter [40, 41]. Thus, with an increase of the feed rate, there is a corresponding increase in the diameter of the fibers. It is worth noting that fibers with beads are formed when the feed rate of solution is too high due to not providing enough time for solvent evaporation $[42,43]$. 
2.4.3. Applied Voltage. The applied voltage to the solution is also an important parameter. This is because fiber formation only occurs when the applied voltage surpasses the threshold voltage (about $\sim 1 \mathrm{KV} / \mathrm{cm}$, dependent on the gel solution). In most cases, applied voltage affects fiber diameter, but the level of significance varies with other parameters such as the polymer solution concentration and the distance between the tip and the collector [44]. As previously discussed, an increase in the applied voltage increases the electrostatic force on the solution, which favors the stretching of the jet, ultimately leading to reduction in the fiber diameter. It has been found that changing the applied voltage will change the shape of the initial drop thereby resulting in a change in the structure and morphology of the fibers [45].

2.4.4. Tip to Collector Distance. Both the diameters and the morphology of the nanofibers can be also controlled by the distance between the tip and the collector, although the effect is not as notable as the other previously mentioned parameters [46]. A minimum distance that enables enough time for solvent evaporation before the fibers reach the collector is required in the process of electrospinning. Longer distance has yielded thinner fibers [47]. Beads would produce when the distance was too far or too close $[48,49]$.

2.5. Material Properties of Electrospun Nanofibers. NFs exhibit numerous fantastic properties in several fields such as optics, electricity, mechanics, thermotics, magnetics, and chemistry due to their surface effect, small-size effect, interface effect, and quantum size effect. The most direct impact of quantum size effect is the blueshift of the boundary of the absorption spectrum. Thus, photon-generated charge carriers transfer to the surface more easily and the smallsize effect gives rise to a high extinction coefficient that all ultimately lead to high quantum efficiency. Additionally, the NFs prepared by electrospinning have a high surface areato-volume ratio (SVR), high porosity, and a unique web structure that are crucial to energy conversion and storage.

2.5.1. Surface Area-to-Volume Ratio. In terms of the outstanding feature of SVR, it has been found that the NFs with higher SVR show enhanced dye adsorption and faster charge transport. Therefore, electrospun NFs can be used as solar energy conversion materials for energy devices such as dyesensitized solar cells and hydrogen generators. High SVR also enables NFs to form a nonwoven structure thereby producing good ionic conductivity [50]. Thus, electrospun NFs can be used as separator materials in fuel cells and batteries.

2.5.2. Porosity. The high porosity of nanofiber structures is necessary for their application in hydrogen storage. For example, when electrospun graphite nanofiber structures with small pores are used as hydrogen storage materials, hydrogen molecules can enter and aggregate between layers of graphite through pores on the NFs surface leading to a high storage capacity [51].

In summary, it is these unique properties that make electrospun nanofiber materials more attractive to be used in many areas like environmental modification, energy, medicine, and water filtration.
2.6. Advantages and Disadvantages of Electrospinning. Numerous aforementioned methods have been used to manufacture NFs and electrospinning is regarded as a versatile and simple method to generate ultrafine fibers that are between tens of nanometers and several micrometers in diameter using a rich variety of materials that includes polymers, inorganic materials, and composite materials. It is worth noting that electrospinning is a continuous process that results in the formation of longer fibers compared to fibers prepared by other chemical or physical methods [52]. Tunable morphologies and structures can produce desired properties by controlling the process parameters and/or designing special electrospinning apparatus.

2.6.1. Advantages. A unique advantage of electrospinning is that complex hierarchical structures can be obtained via controlled calcination [53]. These complex structures are difficult to fabricate using conventional approaches like templateassisted synthesis, self-assembly, CVD, and other solutionbased methods.

Wet-chemistry methods such as polyol method $[54,55]$, hydrothermal method [56, 57], and sol-gel synthesis [58, 59] have also been adopted to synthesize NWs. Of these, hydrothermal method has been viewed as one of the efficient fabrication methods of inorganic nanomaterials. Specifically, $\mathrm{TiO}_{2}$ NWs produced by this method have advantages of fine and controllable crystal form and good dispersibility. However, compared to electrospun NWs (see Figure 7(a)), NWs synthesized via the hydrothermal method (see Figure 7(b)) typically have a lower aspect ratio, which is crucial to charge transfer in energy devices such as LIBs and hydrogen generators. In addition, the disadvantages of hydrothermal method such as relatively long production cycle, rigid temperature, and pressure conditions make electrospinning more attractive. NWs prepared by sol-gel tend to display larger aggregated structures, which negatively affect their performance in an energy device. Considering the lengthy and complex procedures in the milling of NWs prepared by sol-gel (see Figure $7(\mathrm{c})$ ), sol-gel is inferior to electrospinning. Generally speaking, electrospinning is a comprehensive, simple, and advantageous approach for fabrication of NWs or NFs.

2.6.2. Disadvantages. Electrospinning currently has several limitations. First, in the preparation of organic NFs, the variety of polymers used in electrospinning is limited and the structure and performance of NFs are not well researched. Second, the performance and range of application of electrospun inorganic NFs have been limited due to their friability after calcination, although inorganic NFs have a potential application in many fields such as energy devices, high temperature filtration, biological tissue engineering, and efficient catalysis. Third, electrospinning has been implemented at industrial level; however, in terms of producing fibers for the application of filters electrospinning is inferior to traditional methods due to its higher cost to produce fibers with large diameter. Furthermore, it remains a challenge to fabricate NFs with diameters less than $10 \mathrm{~nm}$ by electrospinning [16]. 


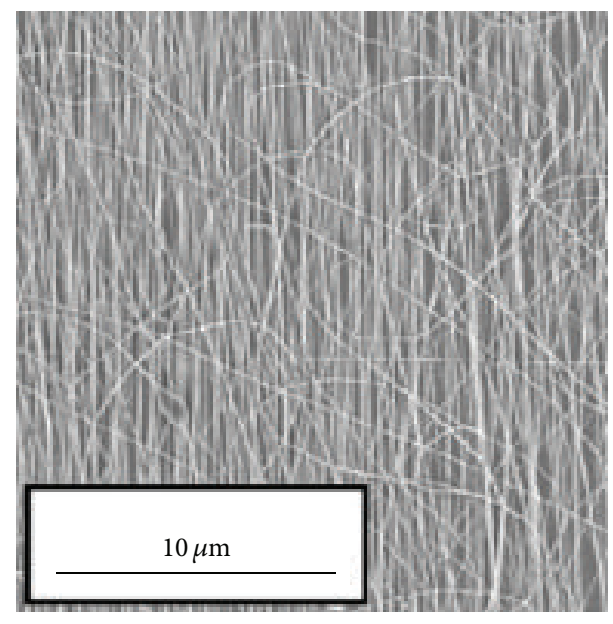

(a)

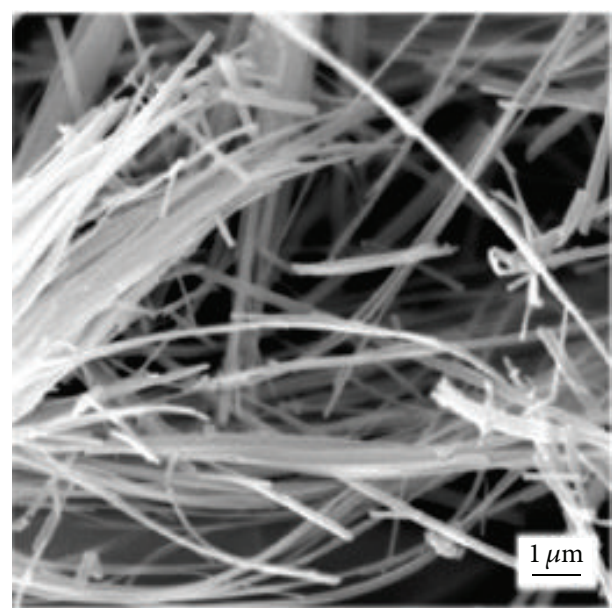

(b)

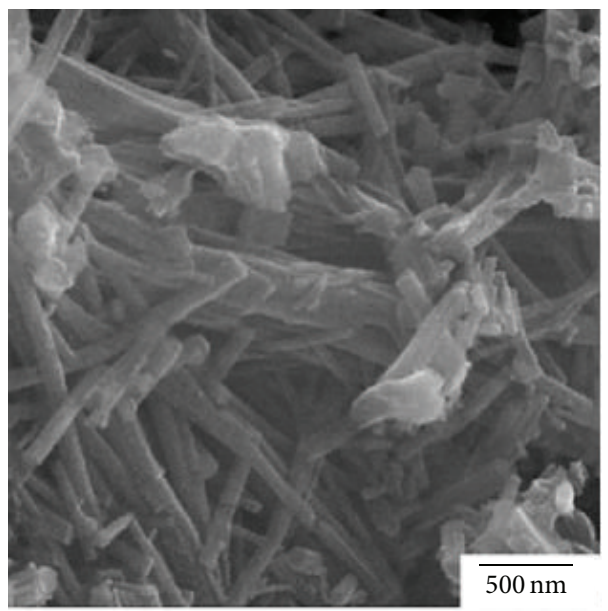

(c)

Figure 7: SEM images of (a) electrospun $\mathrm{TiO}_{2} \mathrm{NWs}$ on a flat substrate (adapted from [60]). (b) Anatase $\mathrm{TiO}_{2} \mathrm{NWs}$ prepared by hydrothermal method (reproduced from [61]). (c) $\mathrm{TiO}_{2}$ NWs prepared by sol-gel synthesis method at $400^{\circ} \mathrm{C}$ (reproduced from [59]).

\section{Applications in Energy Devices of Electrospun NFs}

\subsection{Energy Harvesting and Conversion Devices}

3.1.1. Solar Cells. In 1954, Chapin et al. developed the first piece of crystalline silicon solar cells with $4.5 \%$ conversion efficiency, which opened up a new era in the use of solar energy [62]. Since then, the solar energy technology development has gone through three stages: monocrystalline and polycrystalline silicon solar cells, amorphous silicon thin film solar cells, and the third generation solar cells referring to new concept solar cells with high conversion efficiency such as the dye-sensitized solar cells and hybrid solar cells. While many advances have been made in photovoltaic devices, efforts still need to be made to dramatically improve the conversion efficiency of photovoltaic cells. One efficient strategy is the introduction of new structured materials like electrospun nanofiber materials.

\section{(1) Dye-Sensitized Solar Cells}

(a) Photoanode. Dye-sensitized solar cells (DSSCs) can directly convert light into electricity with the help of a photosensitizing dye. A typical DSSC consists of three primary components: a photoanode, a counter electrode, and an electrolyte. A photoanode is generally composed of a transparent conducting glass coated with a porous semiconductor film, and the photosensitizing dye is adsorbed on this semiconductor film. In DSSCs, once the photosensitizer absorbs photons, the photoelectrons first move into the conducting band of the semiconductor from the photosensitizer and are collected on the photoanode. The photoelectrons further transfer to the counter electrode through the external circuit to form current. In this process, the maximum light absorption and efficient charge transport affect the overall photoelectric conversion efficiency. Hence, the photoanode plays a vital role. Electrospun metal oxide nanofibers as a thin film coated with photoanode have been a hot research topic due to their 


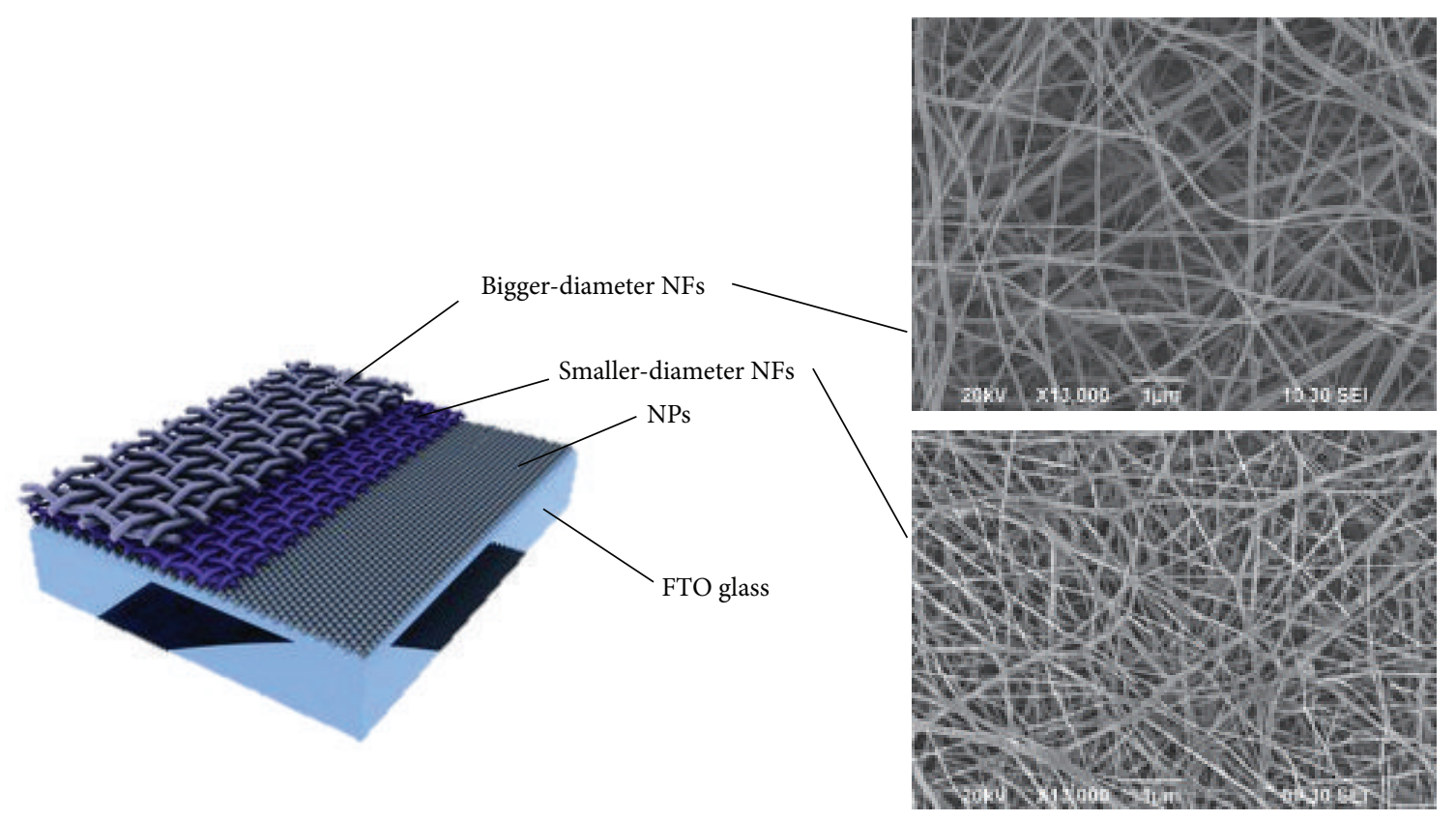

FIGURE 8: SEM images of the bilayer $\mathrm{TiO}_{2}$ nanofibers photoanode of a dye-sensitized solar cell (adapted from [74]).

high specific surface area and 1D fibrous morphology. The high specific surface area enhances the absorption of photosensitizing dye. In contrast to those sintered nanoparticles, 1D fibrous morphology has lower grain boundaries attributes to its improved interconnectivity and high surface areas, which leads to better charge conduction and reduced charge-carrier recombination $[63,64]$. In addition, the large and controllable pore sizes of electrospun NFs contribute to the penetration of viscous polymer gel electrolyte [65].

$\mathrm{TiO}_{2}$ anatase NFs prepared by electrospinning have been mainly used as photoanode material [66-68]; however, one of the major problems is their poor adhesion to conductive substrate. Many effective methods have been adopted to solve the problem, such as converting electrospun nanofibers into nanorods [69], using hot press pretreatment [70], and introducing ultrathin surface treatment layer (STL) [71]. Additionally, some efforts have been made on $\mathrm{TiO}_{2}$ composites (especially for NPs incorporated in NFs), which are used as a photoanode of DSSCs. This is mainly because, when NPs are incorporated in electrospun NFs, the NPs enable the NFs/mats excellent performance [72]. For example, Wang et al. introduced a free-standing nonwoven composite of hybrid nanofibrous $\mathrm{TiO}_{2} / \mathrm{SiO}_{2}$ mat and $\mathrm{TiO}_{2}$ nanoparticles. The DSSC based on this composite photoanode achieves a power conversion efficiency of $6.67 \pm 0.33 \%$ on FTO/glass substrate. It is believed that the $\mathrm{TiO}_{2}$ nanoparticles enhance the dye loading, while the $\mathrm{TiO}_{2}$ NFs improve the electron transport and the $\mathrm{SiO}_{2} \mathrm{NFs}$ provide the mechanical strength and flexibility [73]. Similarly, Yang and Leung [74] prepared an innovative coexistence of $\mathrm{TiO}_{2} \mathrm{NPs} / \mathrm{NFs}$ comprising both smaller-, larger-diameter electrospun $\mathrm{TiO}_{2}$ NFs and $\mathrm{TiO}_{2}$ NPs, which served as a photoanode of DSSCs (as shown in Figure 8). In their study, the power conversion efficiency
(PCE) reached $8.40 \%$, which could be explained by the following effects. First, the $\mathrm{TiO}_{2} \mathrm{NF}$ packed with highly crystalline $\mathrm{TiO}_{2}$ grains not only could provide a large surface area to improve photon absorption but also could enhance the transport and collection of electrons. Second, the biggerdiameter fiber layer could work as the light-scattering that reduces the transmission of incident light and makes the light repeatedly used and thereby increases the photocurrent density [75].

(b) Counter Electrodes. In DSSCs, the counter electrode (CE) plays a role in transmitting and collecting electrons and the catalytic activity of $\mathrm{CE}$ affects the device's internal series resistance, resulting in a change of fill factor [76]. The traditional used counter electrode in DSSCs is platinum $(\mathrm{Pt})$ as a result of its high electrocatalytic activity and high photovoltaic performances with $\mathrm{I}_{3}{ }^{-} / \mathrm{I}^{-}$redox couples [77]. However, $\mathrm{Pt}$ is expensive and the long-term stability of the DSSCs based on Pt CE is unsatisfactory due to the corrosive $\mathrm{I}_{3}{ }^{-} / \mathrm{I}^{-}$redox couple. In order to overcome these problems, many studies have been carried out on alternative counter electrodes such as carbonaceous materials (graphite [78], mesoporous carbon (C) [79], and CNTs [80]) that are integrated into transition metal compounds to replace Pt [81]. Additionally, Joshi et al. [82] prepared electrospun carbon NFs and found that the short circuit current density $\left(J_{\mathrm{sc}}\right)$ and open circuit voltage $\left(V_{\text {oc }}\right)$ of such CNFs based cells were comparable to that of Pt-based cells, but the efficiency was different. The relatively lower performance of the carbon NFs based cells is mainly attributed to their lower fill factor (FF) caused by high series resistance, which was probably improved by fabricating thinner and highly porous CNFs in order to reduce the thickness of the CE. Noh et al. [83] synthesized electrospun 
TABLE 1: Photovoltaic parameters of the DSSC devices with respect to different counter electrodes made of electrospun nanofibers obtained under air-mass (AM) 1.5 illumination at $100 \mathrm{~mW} / \mathrm{cm}^{2}$.

\begin{tabular}{|c|c|c|c|c|c|c|c|}
\hline Counter electrode & Fiber diameter $(\mathrm{nm})$ & $R_{s}\left(\Omega / \mathrm{cm}^{2}\right)$ & $V_{\mathrm{oc}}(\mathrm{V})$ & $J_{\mathrm{sc}}\left(\mathrm{mA} / \mathrm{cm}^{2}\right)$ & FF & $\eta(\%)$ & Ref. \\
\hline PtNFs & $40-70$ & 71 & 0.81 & 12.3 & 60.4 & 6.0 & [76] \\
\hline CNFs & 250 & 15.5 & 0.76 & 12.6 & 0.57 & 5.5 & [82] \\
\hline CNFs + PtNPs & $140-160$ & NA & 0.66 & 13.54 & 49.81 & 4.47 & [83] \\
\hline $\mathrm{Cu}_{2} \mathrm{ZnSnS}_{4} \mathrm{NFs}$ & $30-40$ & 69 & 0.574 & 8.42 & 65 & 3.9 & [84] \\
\hline
\end{tabular}

$\mathrm{CNF}$ /Pt nanocomposites combining with different amounts of Pt nanoparticles. DSSCs fabricated with CNF/Pt nanocomposites (with $40 \mathrm{wt} \%$ Pt nanoparticle) exhibit much better $J_{\mathrm{sc}}, V_{\mathrm{oc}}, \mathrm{FF}$, and photoconversion efficiency $(4.47 \%)$ than do those with CNF only and CNF/Pt nanocomposites do (with $20 \mathrm{wt} \% \mathrm{Pt}$ nanoparticles). This is because the presence of well-distributed Pt nanoparticles on the CNFs improves the electrocatalytic activity with the $\mathrm{I}^{-} / \mathrm{I}_{3}{ }^{-}$electrolyte. Recently, Mali et al. [84] have fabricated kesterite $\mathrm{Cu}_{2} \mathrm{ZnSnS}_{4}$ (CZTS) NFs by electrospinning process. Using cellulose acetate solvent counter electrode, DSSCs achieve higher conversion efficiency than Pt-based CE due to lower interfacial recombination between the counter electrode and electrolyte and lower series resistance. And the photovoltaic performances of electrospun nanofibers counter electrodes mentioned above are summarized in Table 1.

(c) DSSCs Electrolytes. Although the power conversion efficiency (PCE) of DSSC based on liquid electrolyte has surpassed $11 \%$ [85], the leakage and volatilization of liquid electrolytes result in a poor long-term stability, thereby restricting the practical application of DSSCs. To address this issue, inorganic or organic hole conductors, ionic liquids, and polymer gel electrolytes have been investigated as replacements for liquid electrolytes in DSSCs [86]. It is worth noting that polymer gel electrolyte employed in quasi-solidstate DSSCs has attracted wide attention from researchers due to their high thermal stability, good permeability into the mesoporous $\mathrm{TiO}_{2}$ electrode and the counter electrode, and high ionic conductivity [87]. The commonly used polymer gel electrolytes for quasi-solid-state DSSCs include polyacrylonitrile (PAN), polymethylmethacrylate (PMMA), and poly(vinylidenefluoride-co-hexafluoropropylene) (PVDFHFP), among which, PVDF-HFP exhibits relatively high stability and ionic conductivity at room temperature. However, the major drawbacks of these polymer gel electrolytes are complex preparation technology and lower PCE. To overcome these problems, electrospun polymer gel electrolytes membranes have been examined. For instance, Kim et al. [88] fabricated electrospun PVDF-HFP nanofibers films and spincoated PVDF-HFP films that were applied to the polymer matrix in polymer electrolytes for DSSCs. The experimental results have shown that the DSSC devices using electrospun PVDF-HFP nanofiber films exhibited higher PCE than that of DSSC devices using spin-coated PVDF-HFP films because of their high porosity and electrolyte uptake and 1D fiber morphology. It was evident that, with increasing the ionic conductivity of electrospun PVDF-HFP nanofiber films, the photocurrent density of DSSC devices decreased.
Therefore, it indicates that photocurrent density and efficiency of DSSC using electrospun PVDF-HFP nanofibers in electrolytes are not necessarily proportional to the ionic conductivity in electrolytes. In addition, Sethupathy et al. [89] prepared PVdF-PAN-V $\mathrm{O}_{5}$ electrolyte nanofiber membrane by electrospinning technique and such composite nanofiber membrane based DSSCs showed a $V_{\text {oc }}$ of $0.78 \mathrm{~V}$, a FF of 0.72 , and a $J_{\mathrm{sc}}$ of $13.8 \mathrm{~mA} \mathrm{~cm}^{-2}$ at an incident light intensity of $100 \mathrm{~mW} \mathrm{~cm}^{-2}$ leading to a photovoltaic efficiency of $7.75 \%$. It has been demonstrated that such improved photovoltaic performances can be attributed to the high liquid electrolyte uptake resulting from the excellent porosity of composite nanofiber membrane.

3.1.2. Fuel Cells. Fuel cells are energy devices that can convert chemical energy into electrical energy through the redox reaction between anode and cathode. However, unlike batteries, fuel cells store the reactants externally instead of internally and enable the continuous production of electricity under the condition of sustaining supply of fuel (commonly hydrogen and methanol). Among all types of fuel cells, proton exchange membrane fuel cells (PEMFCs) and direct methanol fuel cells (DMFCs) have been considered to be the potential candidate for industrializing due to their high power density and low operating temperature. Compared with PEMFC, DMFC exhibits more advantages such as nonexisting hydrogen preparation, storage, transportation and security problems, fuel feed directly without external reforming process, simple structure, short response time, and easiness of operation.

(a) Electrospun Catalyst-Supports. The usage of a high cost $\mathrm{Pt}$ catalyst in DMFCs limits their value of commercialization. To overcome this problem, exploring new materials or Ptcatalyst-supporting materials as electrocatalyst is essential. In recent years, many researches have been focusing on novel nanostructured carbon materials such as NTs [90, 91] and NFs [92-94] for catalyst-supports in DMFCs due to their good electronic conductivity and low cost. Indeed, the specific 1D morphology can improve the stability of the support materials as well as the overall better performances of resulting electrodes. Electrospinning has been considered as a synthesis technique for carbon materials with controlled diameters and structures. PAN [95], polyaniline (PANI) [96], and polyimide (PI) [97] have been widely used to produce electrospun carbon NFs or NTs as supporting materials and substitutes of Pt catalyst because of their higher porosity and larger specific surface area that are favored for the uniform dispersion of $\mathrm{Pt}$ nanoparticles. For instance, Li et al. [98] 
TABLE 2: The summary of electrospun proton conducting polymers as electrolyte membrane of fuel cells.

\begin{tabular}{|c|c|c|c|c|}
\hline Polymer & Solvent & Carrier polymer & Proton conductivity $(\mathrm{mS} / \mathrm{cm})$ & Ref. \\
\hline Nafion & Methanol & $0.1 \mathrm{wt} \% \mathrm{PEO}$ & $1.5\left(30^{\circ} \mathrm{C}\right.$ and $\left.90 \% \mathrm{RH}\right)$ & [106] \\
\hline NTDA-BDSA-r-APPF & DMF & None & $1.31\left(80^{\circ} \mathrm{C}\right.$ and $\left.98 \% \mathrm{RH}\right)$ & [107] \\
\hline PFSA & Methanol/water & $1 \mathrm{wt} \%$ PEO & $0.16\left(80^{\circ} \mathrm{C}\right.$ and $\left.80 \% \mathrm{RH}\right)$ & [102] \\
\hline PFSA & Methanol/water & $50 \mathrm{wt} \% \mathrm{PEO}$ & $0.041\left(80^{\circ} \mathrm{C}\right.$ and $\left.80 \% \mathrm{RH}\right)$ & [102] \\
\hline
\end{tabular}

investigated Pt clusters electrodeposited on the electrospun carbon nanofibrous mats (CFMs) through a multicycle CV method for DMFC applications. Compared to commercial $\mathrm{Pt} / \mathrm{C}$, such carbon nanofibers enhance the catalytic peak current of methanol revealing that the $1 \mathrm{D}$ structure of the carbon mat is favorable to the catalytic performance of the catalyst. In another study, Pt/C supported by CNFs showed higher electrocatalytic activity, better stability, a larger exchange current, and a smaller charge transfer resistance than that supported by commercial carbon paper, which was attributed to a smaller contact resistance between the catalyst particles and the support material with a good dispersion of catalyst particles into the CNF mats [99]. In addition, another group has investigated such a material as Pt-free electrocatalyst. Guo et al. [100] synthetized non-Pt nitrogen-doped CNTs/CNFs composite (NCNT/CNFs) by electrospinning as an efficient cathode catalyst for the oxygen reduction reaction in fuel cells. It was believed that the enhanced catalytic activity and better long-term stability can be mainly ascribed to pyridinic$\mathrm{N}$ doping and unique three-dimensional network structures.

(b) Electrospun Electrolyte Membrane. Proton exchange membrane (PEM) is another important component of fuel cells. The proton conductivity and fuel crossover are two factors that affect the energy conversion efficiency. Nafion has been typically used as the commercial polymer electrolyte membrane exhibiting relative high proton conductivity that is derived from its unique chemical structure [101]. Electrospinning of Nafion perfluorosulfonic acid (PFSA) polymer has stimulated recent interest. However, Nafion alone is difficult to electrospin and requires the presence of a high molecular weight carrier polymer such as PEO [102], poly(acrylic acid) (PAA) [103], or poly(vinyl alcohol) (PVA) [104] in the electrospinning solution due to its insolubility in alcohol/water solutions and in common organic solvents [105]. The presence of such carrier polymer has been found to reduce the proton conductivity and thus more recent studies have focused to minimize the carrier polymer content. A study by Dong et al. [106] indicated that the high purity Nafion nanofiber via electrospinning with the use of only $0.1 \mathrm{wt} \%$ carrier polymer was successfully obtained, which showed an order of magnitude higher of proton conductivity as compared to the bulk Nafion film. That the proton conductivity increases sharply with decreasing fiber diameter was also observed. They attributed these findings to the alignment of the ionic aggregates along the fiber axis direction that was believed to occur during electrospinning. Similarly, Tamura et al. [107] synthesized a composite electrolyte membrane composed of sulfonated polyimide NFs and sulfonated polyimide for PEMFCs and found that the polyimides within nanofiber were significantly oriented when electrospun. Such composite membrane in the parallel direction exhibited significantly higher proton conductivity than the cast films without nanofibers. Mollá and Compañ [104] prepared the composite membrane containing Nafion infiltrated into a porous mat which was obtained via electrospinning of an aqueous solution of PVA. This composite membrane showed lower proton conductivity due to the carrier polymer used than the pristine Nafion cast membrane but other properties of the membrane like hydrolytic and mechanical stability or reduced methanol permeability were remarkably improved. Therefore, both membranes achieved comparable performance in the DMFCs test. Additionally, the fillers such as $\mathrm{SiO}_{2}, \mathrm{TiO}_{2}$, and zirconium phosphate possibly enhanced water retention and thermal stability and improved the issue of methanol crossover when they were dispersed into acidic membranes [108-110]. And the overview of electrospun proton conducting polymers as electrolyte membrane of fuel cells mentioned above is presented in Table 2.

\subsubsection{Mechanical Energy Harvesters}

(1) Nanogenerators. Mechanical nanogenerators are generally made of piezoelectric nanomaterials, which could harvest small mechanical vibrations from ambient environment and further convert them into electricity to power micro/nanodevices. These nanogenerators are mainly existing in the form of film-based [111, 112], nanowire-based [113], and nanofiber-based structures. Electrospinning technique has the unique advantage in the preparation of nanofiberbased generators.

Piezoelectric polymer PVDF nanofiber has been extensively studied due to its flexibility, ultralong length, and long-term stability compared with normal inorganic piezoelectric materials. Considering the simultaneous stretching and polarization in one-pot to form NFs, electrospinning is an ideal way to produce $\beta$-phase piezoelectric PVDF NFs [114]. The common crystal structure of PVDF is shown in Figure 9(a). Chang et al. prepared a nanogenerator made of single PVDF nanofiber using direct-write electrospinning method (as shown in Figure 9(b)) [115]. Their nanogenerator has a feature that piezoelectric power was generated along the fiber length direction. Later, Fang et al. fabricated a nanogenerator from randomly oriented electrospun PVDF nanofiber membrane in which piezoelectric power was generated perpendicular to fiber length direction. However, the mechanism of this phenomenon is not clear yet [116]. 


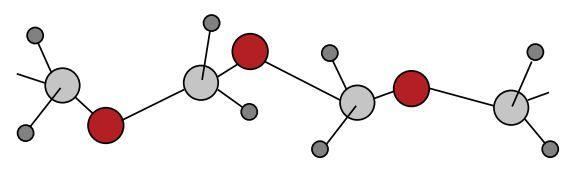

Nonpolar $\alpha$-phase
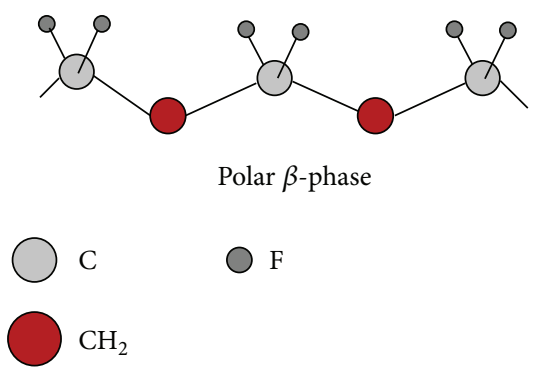

$\mathrm{F}$

(a)

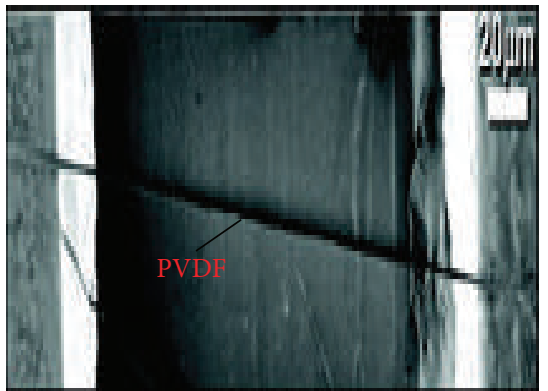

(b)
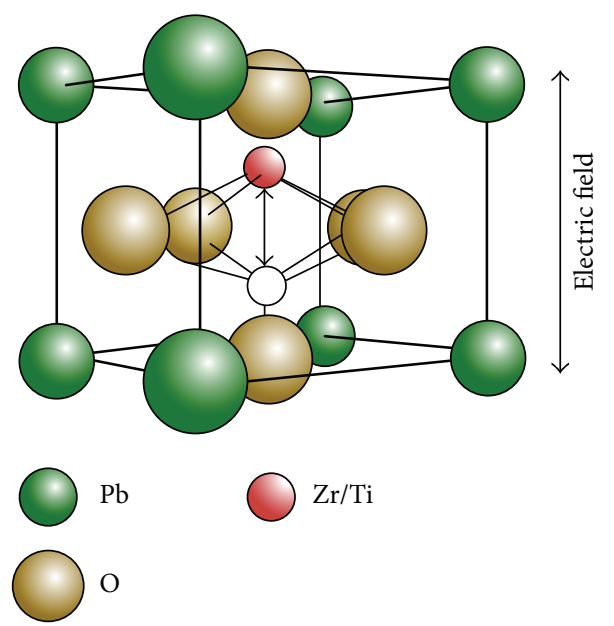

(c)

FIgURE 9: (a) Schematic diagrams showing crystalline structures of PVDF: (top) nonpolar and (bottom) polar. (b) Scanning electron microscope (SEM) image of a nanogenerator comprised of a single PVDF nanofiber, two metal contact electrodes, and a plastic substrate. (c) Schematic diagrams showing crystalline structures of PZT (adapted from $[114,115]$ ).

Furthermore, lead zirconate titanate (PZT), a kind of ceramic material with excellent piezoelectric performance, has been utilized to fabricate nanogenerators recently. The common crystal structure of PZT is shown in Figure 9(c). In a recent publication, Chen et al. [117] reported a piezoelectric nanogenerator based on PZT NFs prepared by electrospinning. The PZT continuous NFs with diameters ranging from $60 \mathrm{~nm}$ to $500 \mathrm{~nm}$ and their highest output voltage and power were $1.63 \mathrm{~V}$ and $0.03 \mu \mathrm{W}$, respectively. Similarly, Zhang et al. [118] have also prepared NFs using the sol-gel electrospinning method. It was found that the output voltage increased with intensified strain and the peak output voltage was $0.17 \mathrm{~V}$. The above results reveal that PZT NFs have great potential for nanogenerator and nanobattery applications with the advantages of higher piezoelectric voltage constant and dielectric constant compared with piezoelectric semiconductor NFs or NWs. However, there are two problems that need to be solved in the application of PZT nanofiber-based generators. First, in order to improve the piezoelectric performance of PZT, a higher annealing temperature $\left(>600^{\circ} \mathrm{C}\right)$ is needed. Second,
PZT and the solvent should be mixed uniformly, which will result in the decrease of the concentration of PZT and the energy conversion efficiency.

In order to produce nanofibers with high piezoelectricity, these parameters in electrospinning process must be optimized: materials, solvents, concentrations, electrical bias, needle-to-electrode distance, and electrospinning methodologies.

\subsubsection{Solar-Driven Hydrogen Generation}

(1) Hydrogen Generators-Photocatalysts. Solar energy is an inexhaustible and clean energy source; meanwhile hydrogen energy is an efficient, clean, and environmentally friendly energy source. To make full use of solar energy, photocatalytic water splitting for hydrogen generation is a potential solution to the energy problem. The reaction mechanism of photocatalytic water splitting is described as follows: (a) absorption of photons to form electron-hole $\left(\mathrm{e}^{-} / \mathrm{h}^{+}\right)$ pairs, (b) charge separation and migration of photogenerated 
charge carriers, and (c) construction of the active sites for redox reactions. Hence, the photocatalyst should meet the following basic conditions in order to completely decompose water. First, the band gap of photocatalyst must be larger than the theoretical decomposition energy of water. Second, photogenerated carrier (electrons and holes) potential must satisfy the requirement for reducing water into hydrogen and oxygen, respectively.

In 1972, Fujishima and Honda first reported hydrogen generated from the photoelectrochemical cells via ultraviolet light irradiation in which $\mathrm{TiO}_{2}$ acted as a photoanode [119]. It is a significant discovery that indicates people can take advantage of solar energy to obtain clean hydrogen fuel by using semiconductor materials as photocatalyts. In recent years, scholars have investigated other semiconductor materials used as a photocatalyst. They carried out studies on hydrogen generation activity of photocatalysts with small bandgap such as $\mathrm{Fe}_{2} \mathrm{O}_{3}$, $\mathrm{WO}_{3}, \mathrm{NaTaO}, \mathrm{CdS}$, and CdSe and other materials, but a stable activity has not yet been found in the visible light wavelength range. After a lot of theoretical study and practical discovery, $\mathrm{TiO}_{2}$ is considered as an ideal photocatalyst due to its long-term stability, low cost, nontoxicity, and so forth. However, its wide band gap (3.2 eV) and narrow range of light absorption result in low efficiency of solar energy utilization and limit its practical application. Therefore, there is no doubt that extending the absorbance range of photocatalytic materials and high efficiency separation of photogenerated carriers will promote more efficient hydrogen generation. To increase the response in the visible light region of $\mathrm{TiO}_{2}$ catalysts, many studies on modification have been done $[120,121]$, including $C, N, S$, and other nonmetallic elemental doping, dyes, and titanium dioxide composites. The experiments have shown that modified photocatalysts possess visible light catalytic activity but poor reactivity of direct carriers.

At present, nanostructured semiconductor catalysts have become a research hotspot in the photocatalytic field due to their enhanced energy conversion efficiency and low cost preparation. These 1D nanostructured fibers exhibit excellent properties with respect to photocatalytic water splitting owing to the small-size effect, high surface effect, and quantum size effect. And it is efficient and of low cost to fabricate organic, inorganic, and hybrid NFs by electrospinning technology compared to other methods. Electrospun NFs with a high specific area-to-volume facilitate effective absorption of light and charge transfer. Choi et al. [122] reported the effects of mesoporosity and interparticle charge transfer on photocatalysis via the comparison of $\mathrm{TiO}_{2}$ nanoparticles and electrospun $\mathrm{TiO}_{2}$ NFs. Zhang et al. [123] reported a novel-structured $\mathrm{TiO}_{2} / \mathrm{SnO}_{2}$ hybrid nanofiber photocatalyst with enhanced photocatalytic activity prepared via the electrospinning method; the heterostructure promotes the photogenerated $\mathrm{e}^{-} / \mathrm{h}^{+}$pair separation. $\mathrm{SnO}_{2}$ possesses a high electron mobility indicating a faster transport of photogenerated electrons. Moreover, the conduction-band edge of $\mathrm{SnO}_{2}$ is more positive than that of $\mathrm{TiO}_{2}$ leading to the migration of photogenerated electrons from the conduction band of $\mathrm{TiO}_{2}$ to that of $\mathrm{SnO}_{2}$. Consequently, the recombination of charge carriers can be suppressed thereby resulting in a higher photocatalytic performance. The photocatalysts based on $\mathrm{TiO}_{2}$ with heterojunction structure obtained from various methods have also been presented by other articles [124-127]. Tong et al. [128] demonstrated a high-performance hydrogen generation system based on the electrospun PAN/Ag/Pd composite nanofibers that was prepared by microwave reducing the electrospun $\mathrm{PAN} / \mathrm{AgNO}_{3}$ nanofibers and followed by a replacement reaction. Those composite nanofibers exhibited excellent catalytic activity, good recycling stability, and easy-separation from the reaction system. Electrospun $\mathrm{Pt}-\mathrm{TiO}_{2} / \mathrm{CNF}$ and $\mathrm{SrTiO}_{3} \mathrm{NFs}$ can also be utilized for solar hydrogen generation $[129,130]$. Liu et al. [131] reported a novel electrospun core-shell $\mathrm{TiO}_{2} / \mathrm{CdSe}$ nanofiber photoanode for photoelectrochemical hydrogen generation.

\subsection{Energy Storage Devices}

3.2.1. Rechargeable Lithium-Ion Batteries. Lithium-ion batteries (LIBs) have become a cornerstone for the development of energy storage technologies and have been applied in many areas including mobile phones, laptop computers, camcorders, digital cameras, and many other commercial and military applications due to their high energy density and long cycle life. LIBs are mainly composed of anode (generally graphite), a carbonate-based organic electrolyte, and a cathode (generally $\mathrm{LiCoO}_{2}$ ). Li ions are intercalated and deintercalated between graphite and $\mathrm{LiCoO}_{2}$ through the electrolyte during discharging and charging. Nanofibers are promising materials for LIBs because of their good electrochemical activity, high mechanical strength, and high specific surface area. In this section, recent advances in the areas of electrospun nanofibrous cathode, anode, and separator materials for LIBs are briefly summarized.

(a) Cathode Materials. $\mathrm{LiCoO}_{2}$ is a typical cathode material used in LIBs due to its high specific capacity, high voltage, and long cycle life. Nanostructured $\mathrm{LiCoO}_{2}$ fiber electrode prepared by electrospinning exhibited enhanced $\mathrm{Li}$ ion and electron conductivity due to the short diffusion distance. As-prepared electrode could display good rate capability and high power density. However, such nanofibrous electrodes have shown poor cycling stability. Regarding this, Cavaliere et al. [64] synthesized the core-shell $\mathrm{LiCoO}_{2} / \mathrm{MgO}$ composite nanofiber by coaxial electrospinning. As-prepared $\mathrm{LiCoO}_{2} / \mathrm{MgO}$ could retain $90 \%$ of its initial charge capacity after 40 cycles compared with $52 \%$ for the fiber electrode without $\mathrm{MgO}$. The enhanced cyclability is attributed to the coating of $\mathrm{MgO}$ which could protect the surface from passive surface film formation during cycling. Besides $\mathrm{LiCoO}_{2}$, $\mathrm{V}_{2} \mathrm{O}_{5}$, and $\mathrm{LiFePO}_{4}$ have also been extensively studied as cathode materials because of their high theoretical specific capacity ( $400 \mathrm{mAh} / \mathrm{g}$ and $170 \mathrm{mAh} / \mathrm{g}$, resp.), good cycling stability, and batter safety. However, both of them suffer low electronic conductivity, leading to low rate capability. The utilization of electrospinning to prepare nanofibrous $\mathrm{V}_{2} \mathrm{O}_{5}$ [132-135], $\mathrm{LiFePO}_{4}[134,135]$, or their respective composite materials cathode electrodes is regarded as the better way to solve these problems. 
(b) Anode Materials. Carbon NFs have been the popular anode materials for LIBs due to several advantages such as low cost, easy availability, and long cycle life. However, there are also some drawbacks about carbon NFs such as relatively low specific capacity and rate capability. Regarding this, C/PAN NFs prepared from electrospinning combined with thermal treatments exhibited higher reversible capacity compared with that of carbon NFs without PAN, which was attributed to their highly disordered structure and defects [136]. Several studies have been also reported on composite C/Si NFs [137], C/Sn NFs [138], and C/MnOx NFs [139] obtained by electrospinning as anode materials for LIBs in terms of cycling stability and electrical conductivity. Recently a simple coaxial electrospinning approach was adopted for the synthesis of hollow $\mathrm{ID}$ anatase $\mathrm{TiO}_{2} \mathrm{NFs}$ as an anode material for lithium-ion batteries by Zhang et al. [22]. When $\mathrm{LiFePO}_{4}$ is used as cathode, the battery showed a high reversible capacity of $103 \mathrm{mAh} / \mathrm{g}$ at a current density of $100 \mathrm{~mA} / \mathrm{g}$ and retained $88 \%$ of its reversible capacity after 300 cycles. Such excellent battery performance was mainly ascribed to the unique structure which provided a large surface area and shortened diffusion pathways of $\mathrm{Li}$ ion and electron. In addition, $\mathrm{Li}$ et al. [140] reported hierarchical $\mathrm{CaCo}_{2} \mathrm{O}_{4}(\mathrm{CCO}) \mathrm{NFs}$ prepared by electrospinning as anode materials for LIBs. It was found that the hierarchical CCONFs exhibited excellent cycling performance and high rate capability.

(c) Separator Materials. Separator is a critical component in LIBs and plays an important role in determining the battery performance. However, the commercial separators based on microporous membranes have several disadvantages, such as low porosity, unsatisfactory thermal stability, and poor wettability in liquid electrolytes [141]. In this regard, electrospun polymer nanofiber membranes provide hope for researchers because of their high porosities, large specific surface areas, and better interconnected conduction pathway for ions within the membrane. Liang et al. [142] reported that PVDF fiber membranes, used as separators for LIBs, prepared by electrospinning combined with heat treatments, exhibited high ionic conductivity at room temperature, a good electrochemical stability, and stable cycle performance. These results indicate that heat-treated PVDF fiber membranes are promising separator candidate for high-performance LIBs. In addition, nanofiber composite membranes including polyvinylidenefluoride-co-chlorotrifluoroethylene (PVDF-CTFE) and PVDF-CTFE/PVDF-HFP were also prepared by electrospinning used as separator membranes for LIBs [141]. Similarly, Jayaraman et al. reported a gelled electrospun PVDFHFP NFs membrane. The separator exhibited the liquid-like conductivity of $\sim 2.9 \mathrm{mS} \mathrm{cm}^{-1}$ at ambient conditions, when it was used as a separator in LIBs where full-cell (electrospun $\mathrm{TiNb}_{2} \mathrm{O}_{7}$ and $\mathrm{LiMn}_{2} \mathrm{O}_{4}$ acted as anode and cathode, resp., as shown in Figure 10) displays excellent cyclability and high rate capability, which is due to faster ionic transport property [143]. Recently electrospun $\mathrm{SiO}_{2} /$ nylon 6,6 nanofiber membranes were fabricated and their electrochemical performance was evaluated for use as separators in LIBs by Yanilmaz et al. [144]. It was found that $\mathrm{SiO}_{2}$ /nylon 6,6 nanofiber

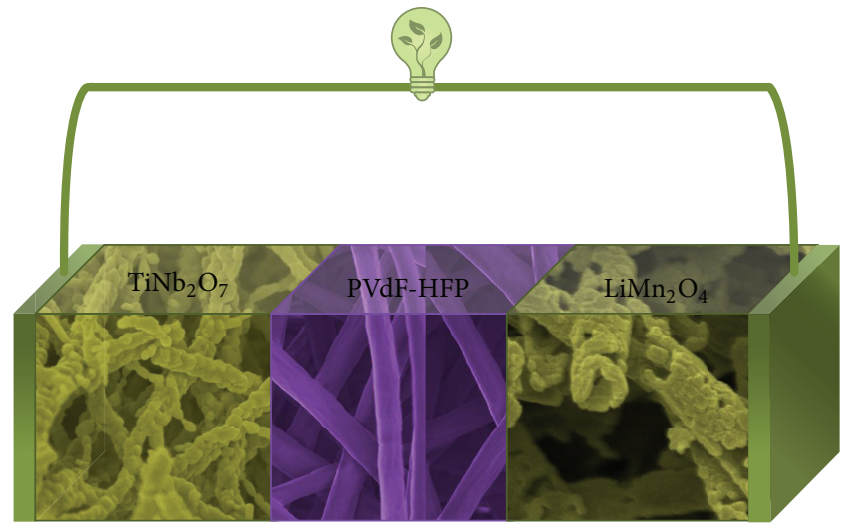

FIgURE 10: Schematic illustration of lithium-ion battery LIBs (the anode, separator, and cathode of lithium-ion battery are made of NFs) (reproduced from [143]).

membranes showed superior thermal stability, mechanical strength, and high porosity. When this $\mathrm{SiO}_{2}$ /nylon 6,6 nanofiber membrane was used as separator, the batteries exhibited good cycling performance and superior rate performance, compared to those using commercial microporous polyolefin membrane.

3.2.2. Supercapacitors. Supercapacitors (SCs) are considered to be one of the most promising new energy storage devices in many areas such as transportation, electricity, communications, defense, consumer electronics, and other applications due to their high power performance, long cycle life, and low maintenance cost. Depending on different energy storage mechanisms, SCs can be classified into pseudocapacitors (PCs) and electrical double layer capacitors (EDLCs). PCs store energy based on fast reversible surface redox reactions, whereas EDLCs store energy using ion adsorption and desorption at the electrode and electrolyte interface. Recently, novel carbon-based materials with rational design of material composition, size, and morphology have been explored for high-performance EDLCs. Electrospinning is perhaps the most facile route to prepare the highly porous nanofibers. Thus, electrospun carbon NFs from polymer precursors such as polybenzimidazole (PBI), PAN, and PI have triggered widespread investigations. And these electrospun CNFs can be utilized as electrode for EDLCs after undergoing the process of stabilization, carbonization, and activation, in which the surface area and porosity of the NFs can be improved. Some studies have also investigated $\mathrm{ZnCl}_{2}$ [145], silver [146], and nickel [147] as additives to the precursor solution in order to enhance the capacitance of electrospun nanofiber-based EDLCs. It has been found that the addition of $\mathrm{ZnCl}_{2}$ has a great influence on fiber morphology and the specific capacitance of carbon NFs containing $5 \mathrm{wt} \%$ $\mathrm{ZnCl}_{2}$ reaches to the highest value of $140 \mathrm{~F} / \mathrm{g}$ when compared to those containing $1 \mathrm{wt} \%$ and $3 \mathrm{wt} \% \mathrm{ZnCl}_{2}$. Furthermore, the coaxial electrospinning technique has been the research hotspot due to its advantage of material preparation. An and Ahn [148] prepared coaxial NFs with different morphologies 
using PVP-doped Sn and a PVP/PAN mixture as inner and outer solution, respectively, by the method of electrospinning combined with the reduction of $\mathrm{H}_{2}$. The electrochemical test has shown that the capacitance of capacitor reaches maximum on the condition that the mass fraction of $\mathrm{Sn}$ is $8 \%$ in the PVP solution. And it is believed that this enhanced electrochemical performance is ascribed to the synergistic effect of active sites on the surface of fibers and pore structure after the reduction of $\mathrm{H}_{2}$.

$\mathrm{RuO}_{2}$ and $\mathrm{V}_{2} \mathrm{O}_{5}$ have also attracted much attention as PCs electrode materials because of their electrochemical stability, high electrical conductivity, and capacitances. For instance, Choi et al. [149] prepared electrospun Pt NFs to support the deposited hydrous $\mathrm{RuO}_{2}$ overlayers and found that the resulting composite electrode showed good performance with a capacity loss of only $21.4 \%$ passing from 10 to $1000 \mathrm{mV} / \mathrm{s}$. Lee et al. [150] reported that the $\mathrm{RuO}_{2}-\mathrm{Ag}_{2} \mathrm{O}$ composite NWs electrode produced from electrospinning exhibited high capacitance of $173.25 \mathrm{~F} / \mathrm{g}$ at $10 \mathrm{mV} / \mathrm{s}$ and excellent retention of capacitance up to $97 \%$ after 300 cycles. However, considering the high cost and toxicity of $\mathrm{Ru}$, researchers recently have focused on conducting polymers such as PANI, polypyrrole (PPy), and poly-p-phenylene (PPP) as electrode materials for PCs. PANI is currently the most promising candidate due to its low cost and high electrical conductivity. Chaudhari et al. [151] have prepared electrospun PANI NF and found that the specific capacitance and rate performance of PANI NFs are much higher than that of PANI powder.

3.2.3. Hydrogen Storage. Hydrogen energy, as one of the important new energy sources in the 21st century, has been considered as an ideal alternative fuel because the only byproduct in its energy conversion process is water. However, the current challenge lies in finding suitable materials that possess the advantages of low cost, durability, and safety in storage of large amount of hydrogen while fulfilling the requirements of vehicular applications in terms of weight, volume, and efficiency. Thus, an efficient hydrogen storage material is crucial to develop and utilize hydrogen energy. And many recent efforts have focused on the super materials for hydrogen storage. It has been found that nanostructured materials are the most promising candidates on account of their unique advantages such as high specific surface area and small pore size, which can facilitate hydrogen storage. Particularly, hydrogen absorption strongly depends on the materials' porosity and the smaller pores provide the higher storage capacity. As such, carbon nanomaterials with tailoring morphology such as carbon NTs and carbon NFs have exhibited high hydrogen storage capacity [152]. As previously discussed, electrospinning is a simple and efficient technique widely used for fabricating fibers with micro- to nanodiameters, controllable pore size, and various morphologies. Ammonia borane (AB) and polystyrene (PS) are used to manufacture core-shell composite NFs using coelectrospinning by Kurban [153]. In this process, PS was selected as the shell material which is mainly because it has a good $\mathrm{H}_{2}$ permeability value (23.8 barrers) and a melting point of approximately $240^{\circ} \mathrm{C}$. The result of the (de)hydrogenation experiment has shown that the significant improvement in the dehydrogenation speed of hydrogen is attributed to the special nanostructure. Several researches have focused on improving hydrogen storage properties such as lower dehydrogenation temperature, alteration of diffusion pathway, and even enhanced reversibility using templates to modified thermodynamics and/or kinetics [154-156]. However, it is upsetting to seek or synthesize a proper template that meets all the requirements for efficient hydrogen storage. Subsequently, Xia et al. [157] developed a novel and freetemplate one-step method to prepare the carbon-coated $\mathrm{Li}_{3} \mathrm{~N}$ NFs via a simple electrospinning technique. The resultant $\mathrm{Li}_{3} \mathrm{~N}$ porous NFs show notably promoted hydrogen storage performance with a stable reversibility over 10 cycles of de/rehydrogenation at temperature of $250^{\circ} \mathrm{C}$. Alipour et al. [158] reported that PMMA/ammonia borane (AB) nanofiber composites were manufactured by electrospinning to study the synergetic nanoconfinement effect of NFs on dehydrogenation temperature and the removal of unwanted byproducts of $\mathrm{AB}$. The experimental results indicated that the PMMA/AB samples can significantly decrease the enthalpy of exothermic decomposition because of the interaction between $\mathrm{AB}$ molecules and PMMA nanofiber structures and vigorously reduce the emission of by-product impurities by decreasing the loss of $\mathrm{AB}$ weight.

Generally speaking, electrospinning can prepare nanomaterials with desired pore size and morphology for hydrogen storage by optimizing process parameters.

\section{Summary and Outlook}

Electrospinning technique is a versatile, efficient, and low cost method for fabrication of NFs of a rich variety of materials. And 1D NFs materials prepared by electrospinning have displayed immense advantages for applications in energy devices such as solar cells, fuel cells, nanogenerators, hydrogen generation and storage, LIBs, and SCs. As for their application in solar cells, electrospun NFs have exhibited high photoelectric conversion efficiency due to efficient charge separation and transport and the maximum light absorption, which is mainly attributed to high specific surface areas and high porosity. Similarly, electrospun NFs, used as photocatalyst, have shown enhanced photocatalytic activity in water splitting for hydrogen generation because of their large SVR and improved crystallinity. Besides, in terms of the application in SCs, the electrode prepared by electrospun NFs has demonstrated high specific capacitance and better cycling stability due to its unique fiber morphology, including large SVR and small diameter. Despite their advantages, the applications of electrospun NFs for energy devices also face some challenges. For instance, in DMFCs, the efficient inhibition of methanol permeation through PEM is an issue that needs to be addressed. Regarding this, developing cathode catalysts that are efficient and durable meanwhile possessing redox activation and stability will be a meaningful direction in the future research. Furthermore, at present, the efficiency of photocatalytic water splitting for hydrogen generation is still unsatisfactory due to the relatively low activity of photocatalysts. Thus, how to prepare novel photocatalysts with high catalytic activity by electrospinning is another problem 
that needs to be solved. With respect to this issue, fabricating electrospun composite organometal halide perovskite/ $/ \mathrm{TiO}_{2}$ NFs or composite organometal halide perovskite/graphene NFs with diversified morphologies as photocatalysts may be a feasible and promising solution. In addition, a combination of the system of photocatalytic water splitting for hydrogen generation and PEMFCs where hydrogen is used as fuel will be extremely useful in the near future. Such combination is environmental-friendly, efficient, and of low cost and thus can be commercialized.

\section{Conflict of Interests}

The authors declare that there is no conflict of interests regarding the publication of this paper.

\section{Acknowledgments}

The authors are grateful for the financial supports by a strategic research project (KZ40005001) of the Education Commission, Beijing Municipal Government, and the Oversea Talent Project of Beijing and a special grant for the Advanced Laser Processing and Development project of Beijing.

\section{References}

[1] C. K. Chan, R. N. Patel, M. J. O'Connell, B. A. Korgel, and Y. Cui, "Solution-grown silicon nanowires for lithium-ion battery anodes," ACS Nano, vol. 4, no. 3, pp. 1443-1450, 2010.

[2] J.-K. Yoo, J. Kim, Y. S. Jung, and K. Kang, "Scalable fabrication of silicon nanotubes and their application to energy storage," Advanced Materials, vol. 24, no. 40, pp. 5452-5456, 2012.

[3] B. H. Lee, M. Y. Song, S.-Y. Jang, S. M. Jo, S.-Y. Kwak, and D. Y. Kim, "Charge transport characteristics of high efficiency dyesensitized solar cells based on electrospun $\mathrm{TiO}_{2}$ nanorod photoelectrodes," The Journal of Physical Chemistry C, vol. 113, no. 51, pp. 21453-21457, 2009.

[4] Y. Liu, J. Goebl, and Y. Yin, "Templated synthesis of nanostructured materials," Chemical Society Reviews, vol. 42, no. 7, pp. 2610-2653, 2013.

[5] M. Chi, Y. Zhao, Q. Fan, and W. Han, "The synthesis of $\operatorname{PrB}_{6}$ nanowires and nanotubes by the self-catalyzed method," Ceramics International, vol. 40, no. 6, pp. 8921-8924, 2014.

[6] N. I. Kovtyukhova, B. R. Martin, J. K. N. Mbindyo, T. E. Mallouk, M. Cabassi, and T. S. Mayer, "Layer-by-layer self-assembly strategy for template synthesis of nanoscale devices," Materials Science and Engineering: C, vol. 19, no. 1-2, pp. 255-262, 2002.

[7] H. Zhu, X. Gao, Y. Lan, D. Song, Y. Xi, and J. Zhao, "Hydrogen titanate nanofibers covered with anatase nanocrystals: a delicate structure achieved by the wet chemistry reaction of the titanate nanofibers," Journal of the American Chemical Society, vol. 126, no. 27, pp. 8380-8381, 2004.

[8] A. Formalas, US Patent 1975504, 1934.

[9] Z. Sun, E. Zussman, A. L. Yarin, J. H. Wendorff, and A. Greiner, "Compound core-shell polymer nanofibers by co-electrospinning," Advanced Materials, vol. 15, no. 22, pp. 1929-1932, 2003.

[10] Y. Srivastava, I. Loscertales, M. Marquez, and T. Thorsen, "Electrospinning of hollow and core/sheath nanofibers using a microfluidic manifold," Microfluidics and Nanofluidics, vol. 4, no. 3, pp. 245-250, 2008.
[11] W.-E. Teo, R. Gopal, R. Ramaseshan, K. Fujihara, and S. Ramakrishna, "A dynamic liquid support system for continuous electrospun yarn fabrication," Polymer, vol. 48, no. 12, pp. 34003405, 2007.

[12] S. Jayaraman, V. Aravindan, P. Suresh Kumar, W. C. Ling, S. Ramakrishna, and S. Madhavi, "Synthesis of porous $\mathrm{LiMn}_{2} \mathrm{O}_{4}$ hollow nanofibers by electrospinning with extraordinary lithium storage properties," Chemical Communications, vol. 49, no. 59, pp. 6677-6679, 2013.

[13] K. W. Kim, K. H. Lee, M. S. Khil, Y. S. Ho, and H. Y. Kim, "The effect of molecular weight and the linear velocity of drum surface on the properties of electrospun poly(ethylene terephthalate) nonwovens," Fibers and Polymers, vol. 5, no. 2, pp. 122-127, 2004.

[14] R. Dersch, T. Liu, A. K. Schaper, A. Greiner, and J. H. Wendorff, "Electrospun nanofibers: internal structure and intrinsic orientation," Journal of Polymer Science, Part A: Polymer Chemistry, vol. 41, no. 4, pp. 545-553, 2003.

[15] D. Li, Y. Wang, and Y. Xia, "Electrospinning of polymeric and ceramic nanofibers as uniaxially aligned arrays," Nano Letters, vol. 3, no. 8, pp. 1167-1171, 2003.

[16] S. Ramakrishna, R. Jose, P. S. Archana et al., "Science and engineering of electrospun nanofibers for advances in clean energy, water filtration, and regenerative medicine," Journal of Materials Science, vol. 45, no. 23, pp. 6283-6312, 2010.

[17] C. Sun, J. Shi, D. J. Bayerl, and X. Wang, "PVDF microbelts for harvesting energy from respiration," Energy and Environmental Science, vol. 4, no. 11, pp. 4508-4512, 2011.

[18] D. Hwang, S. M. Jo, D. Y. Kim, V. Armel, D. R. MacFarlane, and S.-Y. Jang, "High-efficiency, solid-state, dye-sensitized solar cells using hierarchically structured $\mathrm{TiO}_{2}$ nanofibers," ACS Applied Materials and Interfaces, vol. 3, no. 5, pp. 1521-1527, 2011.

[19] Y. Liang, D. Wu, and R. Fu, "Carbon microfibers with hierarchical porous structure from electrospun fiber-like natural biopolymer," Scientific Reports, vol. 3, article 1119, 2013.

[20] D. Li and Y. Xia, "Direct fabrication of composite and ceramic hollow nanofibers by electrospinning," Nano Letters, vol. 4, no. 5, pp. 933-938, 2004.

[21] V. Thavasi, G. Singh, and S. Ramakrishna, "Electrospun nanofibers in energy and environmental applications," Energy and Environmental Science, vol. 1, no. 2, pp. 205-221, 2008.

[22] X. Zhang, V. Aravindan, P. S. Kumar et al., "Synthesis of $\mathrm{TiO}_{2}$ hollow nanofibers by co-axial electrospinning and its superior lithium storage capability in full-cell assembly with olivine phosphate," Nanoscale, vol. 5, no. 13, pp. 5973-5980, 2013.

[23] D. Sun, C. Chang, S. Li, and L. Lin, "Near-field electrospinning," Nano Letters, vol. 6, no. 4, pp. 839-842, 2006.

[24] D. Di Camillo, V. Fasano, F. Ruggieri et al., "Near-field electrospinning of light-emitting conjugated polymer nanofibers," Nanoscale, vol. 5, no. 23, pp. 11637-11642, 2013.

[25] C. Chang, K. Limkrailassiri, and L. Lin, "Continuous near-field electrospinning for large area deposition of orderly nanofiber patterns," Applied Physics Letters, vol. 93, no. 12, Article ID 123111, 2008.

[26] G. S. Bisht, G. Canton, A. Mirsepassi et al., "Controlled continuous patterning of polymeric nanofibers on three-dimensional substrates using low-voltage near-field electrospinning," Nano Letters, vol. 11, no. 4, pp. 1831-1837, 2011.

[27] F.-L. Zhou, P. L. Hubbard, S. J. Eichhorn, and G. J. M. Parker, "Jet deposition in near-field electrospinning of patterned polycaprolactone and sugar-polycaprolactone core-shell fibres," Polymer, vol. 52, no. 16, pp. 3603-3610, 2011. 
[28] Y. Y. S. Huang, E. M. Terentjev, T. Oppenheim, S. P. Lacour, and M. E. Welland, "Fabrication and electromechanical characterization of near-field electrospun composite fibers," Nanotechnology, vol. 23, no. 10, Article ID 105305, 2012.

[29] D. S. Engstrom, B. Porter, M. Pacios, and H. Bhaskaran, "Additive nanomanufacturing-a review," Journal of Materials Research, vol. 29, no. 17, pp. 1792-1816, 2014.

[30] J. U. Park, M. Hardy, S. J. Kang et al., "High-resolution electrohydrodynamic jet printing," Nature Materials, vol. 6, no. 10, pp. 782-789, 2007.

[31] S. Mishra, K. L. Barton, A. G. Alleyne, P. M. Ferreira, and J. A. Rogers, "High-speed and drop-on-demand printing with a pulsed electrohydrodynamic jet," Journal of Micromechanics and Microengineering, vol. 20, no. 9, Article ID 095026, 2010.

[32] K. Wang and J. P. W. Stark, "Deposition of colloidal gold nanoparticles by fully pulsed-voltage- controlled electrohydrodynamic atomisation," Journal of Nanoparticle Research, vol. 12, no. 3, pp. 707-711, 2010.

[33] P. Galliker, J. Schneider, H. Eghlidi, S. Kress, V. Sandoghdar, and D. Poulikakos, "Direct printing of nanostructures by electrostatic autofocussing of ink nanodroplets," Nature Communications, vol. 3, article 890, 2012.

[34] S. Yao, X. Wang, X. Liu, R. Wang, C. Deng, and F. Cui, "Effects of ambient relative humidity and solvent properties on the electrospinning of pure hyaluronic acid nanofibers," Journal of Nanoscience and Nanotechnology, vol. 13, no. 7, pp. 4752-4758, 2013.

[35] S. A. Theron, E. Zussman, and A. L. Yarin, "Experimental investigation of the governing parameters in the electrospinning of polymer solutions," Polymer, vol. 45, no. 6, pp. 2017-2030, 2004.

[36] S. de Vrieze, T. van Camp, A. Nelvig, B. Hagström, P. Westbroek, and K. de Clerck, "The effect of temperature and humidity on electrospinning," Journal of Materials Science, vol. 44, no. 5, pp. 1357-1362, 2009.

[37] M. G. McKee, G. L. Wilkes, R. H. Colby, and T. E. Long, "Correlations of solution rheology with electrospun fiber formation of linear and branched polyesters," Macromolecules, vol. 37, no. 5, pp. 1760-1767, 2004.

[38] R. Casasola, N. L. Thomas, A. Trybala, and S. Georgiadou, "Electrospun poly lactic acid (PLA) fibres: effect of different solvent systems on fibre morphology and diameter," Polymer, vol. 55, no. 18, pp. 4728-4737, 2014.

[39] Q. Yang, Z. Li, Y. Hong et al., "Influence of solvents on the formation of ultrathin uniform poly(vinyl pyrrolidone) nanofibers with electrospinning," Journal of Polymer Science Part B: Polymer Physics, vol. 42, no. 20, pp. 3721-3726, 2004.

[40] S. B. Mitchell and J. E. Sanders, "A unique device for controlled electrospinning," Journal of Biomedical Materials Research Part A, vol. 78, no. 1, pp. 110-120, 2006.

[41] W. K. Son, J. H. Youk, T. S. Lee, and W. H. Park, "The effects of solution properties and polyelectrolyte on electrospinning of ultrafine poly(ethylene oxide) fibers," Polymer, vol. 45, no. 9, pp. 2959-2966, 2004.

[42] W. Zuo, M. Zhu, W. Yang, H. Yu, Y. Chen, and Y. Zhang, "Experimental study on relationship between jet instability and formation of beaded fibers during electrospinning," Polymer Engineering \& Science, vol. 45, no. 5, pp. 704-709, 2005.

[43] X. Yuan, Y. Zhang, C. Dong, and J. Sheng, "Morphology of ultrafine polysulfone fibers prepared by electrospinning," Polymer International, vol. 53, no. 11, pp. 1704-1710, 2004.
[44] O. S. Yördem, M. Papila, and Y. Z. Menceloğlu, "Effects of electrospinning parameters on polyacrylonitrile nanofiber diameter: an investigation by response surface methodology," Materials \& Design, vol. 29, no. 1, pp. 34-44, 2008.

[45] P. K. Baumgarten, "Electrostatic spinning of acrylic microfibers," Journal of Colloid and Interface Science, vol. 36, no. 1, pp. 71-79, 1971.

[46] J. Doshi and D. H. Reneker, "Electrospinning process and applications of electrospun fibers," in Proceedings of the Conference Record of the IEEE Industry Applications Society Annual Meeting, vol. 3, pp. 1698-1703, IEEE, Toronto, Canada, October 1993.

[47] A. Hu and A. Apblett, Nanotechnology for Water Treatment and Purification, Springer, Berlin, Germany, 2014.

[48] N. Bhardwaj and S. C. Kundu, "Electrospinning: a fascinating fiber fabrication technique," Biotechnology Advances, vol. 28, no. 3, pp. 325-347, 2010.

[49] J. S. Lee, K. H. Choi, H. D. Ghim et al., "Role of molecular weight of atactic poly(vinyl alcohol) (PVA) in the structure and properties of PVA nanofabric prepared by electrospinning," Journal of Applied Polymer Science, vol. 93, no. 4, pp. 1638-1646, 2004.

[50] C. Yang, Z. Jia, Z. Guan, and L. Wang, "Polyvinylidene fluoride membrane by novel electrospinning system for separator of Liion batteries," Journal of Power Sources, vol. 189, no. 1, pp. 716720, 2009.

[51] D.-K. Kim, S. H. Park, B. C. Kim, B. D. Chin, S. M. Jo, and D. Y. Kim, "Electrospun polyacrylonitrile-based carbon nanofibers and their hydrogen storages," Macromolecular Research, vol. 13, no. 6, pp. 521-528, 2005.

[52] Y.-Z. Long, M.-M. Li, C. Gu et al., "Recent advances in synthesis, physical properties and applications of conducting polymer nanotubes and nanofibers," Progress in Polymer Science, vol. 36, no. 10, pp. 1415-1442, 2011.

[53] P. S. Kumar, J. Sundaramurthy, S. Sundarrajan et al., "Hierarchical electrospun nanofibers for energy harvesting, production and environmental remediation," Energy \& Environmental Science, vol. 7, no. 10, pp. 3192-3222, 2014.

[54] P. Peng, A. Hu, H. Huang, A. P. Gerlich, B. Zhao, and Y. N. Zhou, "Room-temperature pressureless bonding with silver nanowire paste: towards organic electronic and heat-sensitive functional devices packaging," Journal of Materials Chemistry, vol. 22, no. 26, pp. 12997-13001, 2012.

[55] R. Z. Li, A. Hu, T. Zhang, and K. D. Oakes, "Direct writing on paper of foldable capacitive touch pads with silver nanowire inks," ACS Applied Materials \& Interfaces, vol. 6, no. 23, pp. 21721-21729, 2014.

[56] A. Hu, X. Zhang, K. D. Oakes, P. Peng, Y. N. Zhou, and M. R. Servos, "Hydrothermal growth of free standing $\mathrm{TiO}_{2}$ nanowire membranes for photocatalytic degradation of pharmaceuticals," Journal of Hazardous Materials, vol. 189, no. 1-2, pp. 278-285, 2011.

[57] A. Hu, R. Liang, X. Zhang et al., "Enhanced photocatalytic degradation of dyes by $\mathrm{TiO}_{2}$ nanobelts with hierarchical structures," Journal of Photochemistry and Photobiology A: Chemistry, vol. 256, pp. 7-15, 2013.

[58] B. B. Lakshmi, P. K. Dorhout, and C. R. Martin, "Sol-gel template synthesis of semiconductor nanostructures," Chemistry of Materials, vol. 9, no. 3, pp. 857-862, 1997.

[59] M. Rodríguez-Reyes and H. J. Dorantes-Rosales, "A simple route to obtain $\mathrm{TiO}_{2}$ nanowires by the sol-gel method," Journal of Sol-Gel Science and Technology, vol. 59, no. 3, pp. 658-661, 2011. 
[60] Z. Dong, S. J. Kennedy, and Y. Wu, "Electrospinning materials for energy-related applications and devices," Journal of Power Sources, vol. 196, no. 11, pp. 4886-4904, 2011.

[61] Y. X. Zhang, G. H. Li, Y. X. Jin, J. Zhang, and L. D. Zhang, "Hydrothermal synthesis and photoluminescence of $\mathrm{TiO}_{2}$ nanowires," Chemical Physics Letters, vol. 365, no. 3-4, pp. 300304, 2002.

[62] D. M. Chapin, C. S. Fuller, and G. L. Pearson, "A new silicon p-n junction photocell for converting solar radiation into electrical power," Journal of Applied Physics, vol. 25, no. 5, pp. 676-677, 1954.

[63] S. Chuangchote, T. Sagawa, and S. Yoshikawa, "Efficient dyesensitized solar cells using electrospun $\mathrm{TiO}_{2}$ nanofibers as a light harvesting layer," Applied Physics Letters, vol. 93, no. 3, Article ID 033310, 2008.

[64] S. Cavaliere, S. Subianto, I. Savych, D. J. Jones, and J. Rozière, "Electrospinning: designed architectures for energy conversion and storage devices," Energy and Environmental Science, vol. 4, no. 12, pp. 4761-4785, 2011.

[65] J. Fang, X. Wang, and T. Lin, "Functional applications of electrospun nanofibers," in Nanofibers-Production, Properties and Functional Applications, pp. 287-326, InTech, 2011.

[66] K. Mukherjee, T.-H. Teng, R. Jose, and S. Ramakrishna, "Electron transport in electrospun $\mathrm{TiO}_{2}$ nanofiber dye-sensitized solar cells," Applied Physics Letters, vol. 95, no. 1, Article ID 012101, 2009.

[67] Y. Li, D.-K. Lee, J. Y. Kim et al., "Highly durable and flexible dyesensitized solar cells fabricated on plastic substrates: PVDFnanofiber-reinforced $\mathrm{TiO}_{2}$ photoelectrodes," Energy \& Environmental Science, vol. 5, no. 10, pp. 8950-8957, 2012.

[68] H. Krysova, J. Trckova-Barakova, J. Prochazka, A. Zukal, J. Maixner, and L. Kavan, "Titania nanofiber photoanodes for dyesensitized solar cells," Catalysis Today, vol. 230, pp. 234-239, 2014.

[69] K. Fujihara, A. Kumar, R. Jose, S. Ramakrishna, and S. Uchida, "Spray deposition of electrospun $\mathrm{TiO}_{2}$ nanorods for dyesensitized solar cell," Nanotechnology, vol. 18, no. 36, Article ID 365709, 2007.

[70] M. Y. Song, D. K. Kim, K. J. Ihn, S. M. Jo, and D. Y. Kim, "Electrospun $\mathrm{TiO}_{2}$ electrodes for dye-sensitized solar cells," Nanotechnology, vol. 15, no. 12, pp. 1861-1865, 2004.

[71] V. Thavasi, V. Renugopalakrishnan, R. Jose, and S. Ramakrishna, "Controlled electron injection and transport at materials interfaces in dye sensitized solar cells," Materials Science and Engineering R: Reports, vol. 63, no. 3, pp. 81-99, 2009.

[72] C. L. Zhang and S. H. Yu, "Nanoparticles meet electrospinning: recent advances and future prospects," Chemical Society Reviews, vol. 43, no. 13, pp. 4423-4448, 2014.

[73] X. Wang, M. Xi, H. Fong, and Z. Zhu, "Flexible, transferable, and thermal-durable dye-sensitized solar cell photoanode consisting of $\mathrm{TiO}_{2}$ nanoparticles and electrospun $\mathrm{TiO}_{2} / \mathrm{SiO}_{2}$ nanofibers," ACS Applied Materials \& Interfaces, vol. 6, no. 18, pp. 15925-15932, 2014.

[74] L. Yang and W. W.-F. Leung, "Application of a bilayer $\mathrm{TiO}_{2}$ nanofiber photoanode for optimization of dye-sensitized solar cells," Advanced Materials, vol. 23, no. 39, pp. 4559-4562, 2011.

[75] H.-J. Koo, Y. J. Kim, Y. H. Lee, W. I. Lee, K. Kim, and N.-G. Park, "Nano-embossed hollow spherical $\mathrm{TiO}_{2}$ as bifunctional material for high-efficiency dye-sensitized solar cells," Advanced Materials, vol. 20, no. 1, pp. 195-199, 2008.
[76] I. Jeong, J. Lee, K. V. Joseph, H. I. Lee, J. K. Kim, and S. Yoon, "Low-cost electrospun WC/C composite nanofiber as a powerful platinum-free counter electrode for dye sensitized solar cell," Nano Energy, vol. 9, pp. 392-400, 2014.

[77] M. Grätzel, “Dye-sensitized solar cells," Journal of Photochemistry and Photobiology C: Photochemistry Reviews, vol. 4, no. 2, pp. 145-153, 2003.

[78] V.-D. Dao, N. T. Q. Hoa, L. L. Larina, J.-K. Lee, and H.-S. Choi, "Graphene-platinum nanohybrid as a robust and low-cost counter electrode for dye-sensitized solar cells," Nanoscale, vol. 5, no. 24, pp. 12237-12244, 2013.

[79] M. Wu, X. Lin, A. Hagfeldt, and T. Ma, "Low-cost molybdenum carbide and tungsten carbide counter electrodes for dye-sensitized solar cells," Angewandte Chemie International Edition, vol. 50, no. 15, pp. 3520-3524, 2011.

[80] Y. Jo, J. Y. Cheon, J. Yu et al., "Highly interconnected ordered mesoporous carbon-carbon nanotube nanocomposites: Ptfree, highly efficient, and durable counter electrodes for dyesensitized solar cells," Chemical Communications, vol. 48, no. 65 , pp. 8057-8059, 2012.

[81] W. J. Lee, E. Ramasamy, D. Y. Lee, and J. S. Song, "Efficient dyesensitized solar cells with catalytic multiwall carbon nanotube counter electrodes," ACS Applied Materials \& Interfaces, vol. 1, no. 6, pp. 1145-1149, 2009.

[82] P. Joshi, L. Zhang, Q. Chen, D. Galipeau, H. Fong, and Q. Qiao, "Electrospun carbon nanofibers as low-cost counter electrode for dye-sensitized solar cells," ACS Applied Materials \& Interfaces, vol. 2, no. 12, pp. 3572-3577, 2010.

[83] S. I. Noh, T.-Y. Seong, and H.-J. Ahn, "Carbon nanofibers combined with Pt nanoparticles for use as counter electrodes in dye-sensitized solar cells," Journal of Ceramic Processing Research, vol. 13, no. 4, pp. 491-494, 2012.

[84] S. S. Mali, P. S. Patil, and C. K. Hong, "Low-cost electrospun highly crystalline kesterite $\mathrm{Cu}_{2} \mathrm{ZnSnS}_{4}$ nanofiber counter electrodes for efficient dye-sensitized solar cells," ACS Applied Materials \& Interfaces, vol. 6, no. 3, pp. 1688-1696, 2014.

[85] A. Yella, H.-W. Lee, H. N. Tsao et al., "Porphyrin-sensitized solar cells with cobalt (II/III)-based redox electrolyte exceed 12 percent efficiency,' Science, vol. 334, no. 6056, pp. 629-634, 2011.

[86] S. K. Ahn, T. Ban, P. Sakthivel et al., "Development of dyesensitized solar cells composed of liquid crystal embedded, electrospun poly(vinylidene fluoride-co-hexafluoropropylene) nanofibers as polymer gel electrolytes," ACS Applied Materials and Interfaces, vol. 4, no. 4, pp. 2096-2100, 2012.

[87] P. Wang, S. M. Zakeeruddin, J. E. Moser, M. K. Nazeeruddin, T. Sekiguchi, and M. Grätzel, "A stable quasi-solid-state dyesensitized solar cell with an amphiphilic ruthenium sensitizer and polymer gel electrolyte," Nature Materials, vol. 2, no. 6, pp. 402-407, 2003.

[88] J.-U. Kim, S.-H. Park, H.-J. Choi, W.-K. Lee, J.-K. Lee, and M.-R. Kim, "Effect of electrolyte in electrospun poly(vinylidene fluoride-co-hexafluoropropylene) nanofibers on dye-sensitized solar cells," Solar Energy Materials and Solar Cells, vol. 93, no. 6-7, pp. 803-807, 2009.

[89] M. Sethupathy, S. Ravichandran, and P. Manisankar, "Preparation of PVdF-PAN-V2O5 hybrid composite membrane by electrospinning and fabrication of dye-sensitized solar cells," International Journal of Electrochemical Science, vol. 9, no. 6, pp. 3166-3180, 2014.

[90] S. H. Joo, S. J. Choi, I. Oh et al., "Ordered nanoporous arrays of carbon supporting high dispersions of platinum nanoparticles," Nature, vol. 412, no. 6843, pp. 169-172, 2001. 
[91] J.-Y. Jhan, Y.-W. Huang, C.-H. Hsu, H. Teng, D. Kuo, and P.L. Kuo, "Three-dimensional network of graphene grown with carbon nanotubes as carbon support for fuel cells," Energy, vol. 53, pp. 282-287, 2013.

[92] S. Kang, S. Lim, D.-H. Peck et al., "Stability and durability of PtRu catalysts supported on carbon nanofibers for direct methanol fuel cells," International Journal of Hydrogen Energy, vol. 37, no. 5, pp. 4685-4693, 2012.

[93] Z.-G. Zhao, Z.-J. Yao, J. Zhang, R. Zhu, Y. Jin, and Q.-W. $\mathrm{Li}$, "Rational design of galvanically replaced Pt-anchored electrospun $\mathrm{WO}_{3}$ nanofibers as efficient electrode materials for methanol oxidation," Journal of Materials Chemistry, vol. 22, no. 32, pp. 16514-16519, 2012.

[94] W. J. Kim and J. Y. Chang, "Molecularly imprinted polyimide nanofibers prepared by electrospinning," Materials Letters, vol. 65, no. 9, pp. 1388-1391, 2011.

[95] D. Chen, Y.-E. Miao, and T. Liu, "Electrically conductive polyaniline/polyimide nanofiber membranes prepared via a combination of electrospinning and subsequent in situ polymerization growth," ACS Applied Materials \& Interfaces, vol. 5, no. 4, pp. 1206-1212, 2013.

[96] F.-J. Liu, L.-M. Huang, T.-C. Wen, and A. Gopalan, "Large-area network of polyaniline nanowires supported platinum nanocatalysts for methanol oxidation," Synthetic Metals, vol. 157, no. 16-17, pp. 651-658, 2007.

[97] M. Inagaki, Y. Yang, and F. Kang, "Carbon nanofibers prepared via electrospinning," Advanced Materials, vol. 24, no. 19, pp. 2547-2566, 2012.

[98] M. Li, G. Han, and B. Yang, "Fabrication of the catalytic electrodes for methanol oxidation on electrospinning-derived carbon fibrous mats," Electrochemistry Communications, vol. 10, no. 6, pp. 880-883, 2008.

[99] M. Li, S. Zhao, G. Han, and B. Yang, "Electrospinning-derived carbon fibrous mats improving the performance of commercial Pt/C for methanol oxidation," Journal of Power Sources, vol. 191, no. 2, pp. 351-356, 2009.

[100] Q. Guo, D. Zhao, S. Liu, S. Chen, M. Hanif, and H. Hou, "Freestanding nitrogen-doped carbon nanotubes at electrospun carbon nanofibers composite as an efficient electrocatalyst for oxygen reduction," Electrochimica Acta, vol. 138, pp. 318-324, 2014.

[101] A. S. Aricò, V. Baglio, and V. Antonucci, "Direct methanol fuel cells: history, status and perspectives," in Electrocatalysis of Direct Methanol Fuel Cells, H. Liu and J. Zhang, Eds., pp. 1-78, Wiley-VCH, Weinheim, Germany, 2009.

[102] J. Choi, K. M. Lee, R. Wycisk, P. N. Pintauro, and P. T. Mather, "Nanofiber composite membranes with low equivalent weight perfluorosulfonic acid polymers," Journal of Materials Chemistry, vol. 20, no. 30, pp. 6282-6290, 2010.

[103] H. Chen, J. D. Snyder, and Y. A. Elabd, "Electrospinning and solution properties of Nafion and poly(acrylic acid)," Macromolecules, vol. 41, no. 1, pp. 128-135, 2008.

[104] S. Mollá and V. Compañ, "Polyvinyl alcohol nanofiber reinforced Nafion membranes for fuel cell applications," Journal of Membrane Science, vol. 372, no. 1-2, pp. 191-200, 2011.

[105] J. B. Ballengee and P. N. Pintauro, "Morphological control of electrospun nafion nanofiber mats," Journal of the Electrochemical Society, vol. 158, no. 5, pp. B568-B572, 2011.

[106] B. Dong, L. Gwee, D. S.-D. La Cruz, K. I. Winey, and Y. A. Elabd, "Super proton conductive high-purity nafion nanofibers," Nano Letters, vol. 10, no. 9, pp. 3785-3790, 2010.
[107] T. Tamura and H. Kawakami, "Aligned electrospun nanofiber composite membranes for fuel cell electrolytes," Nano Letters, vol. 10, no. 4, pp. 1324-1328, 2010.

[108] U. H. Jung, K. T. Park, E. H. Park, and S. H. Kim, "Improvement of low-humidity performance of PEMFC by addition of hydrophilic $\mathrm{SiO}_{2}$ particles to catalyst layer," Journal of Power Sources, vol. 159, no. 1, pp. 529-532, 2006.

[109] E. Chalkova, M. B. Pague, M. V. Fedkin, D. J. Wesolowski, and S. N. Lvov, "Nafion/ $/ \mathrm{TiO}_{2}$ proton conductive composite membranes for PEMFCs operating at elevated temperature and reduced relative humidity," Journal of the Electrochemical Society, vol. 152, no. 6, pp. A1035-A1040, 2005.

[110] E. Chalkova, M. V. Fedkin, S. Komarneni, and S. N. Lvov, "Nafion/zirconium phosphate composite membranes for PEMFC operating at up to $120^{\circ} \mathrm{C}$ and down to $13 \%$ RH," Journal of the Electrochemical Society, vol. 154, no. 2, pp. B288-B295, 2007.

[111] F.-R. Fan, L. Lin, G. Zhu, W. Wu, R. Zhang, and Z. L. Wang, "Transparent triboelectric nanogenerators and self-powered pressure sensors based on micropatterned plastic films," Nano Letters, vol. 12, no. 6, pp. 3109-3114, 2012.

[112] K.-I. Park, S. Xu, Y. Liu et al., "Piezoelectric $\mathrm{BaTiO}_{3}$ thin film nanogenerator on plastic substrates," Nano Letters, vol. 10, no. 12, pp. 4939-4943, 2010.

[113] B. Kumar and S.-W. Kim, "Recent advances in power generation through piezoelectric nanogenerators," Journal of Materials Chemistry, vol. 21, no. 47, pp. 18946-18958, 2011.

[114] J. Chang, M. Dommer, C. Chang, and L. Lin, "Piezoelectric nanofibers for energy scavenging applications," Nano Energy, vol. 1, no. 3, pp. 356-371, 2012.

[115] C. Chang, V. H. Tran, J. Wang, Y.-K. Fuh, and L. Lin, "Directwrite piezoelectric polymeric nanogenerator with high energy conversion efficiency," Nano Letters, vol. 10, no. 2, pp. 726-731, 2010.

[116] J. Fang, X. Wang, and T. Lin, "Electrical power generator from randomly oriented electrospun poly(vinylidene fluoride) nanofibre membranes," Journal of Materials Chemistry, vol. 21, no. 30, pp. 11088-11091, 2011.

[117] X. Chen, S. Xu, N. Yao, and Y. Shi, "1.6 v nanogenerator for mechanical energy harvesting using PZT nanofibers," Nano Letters, vol. 10, no. 6, pp. 2133-2137, 2010.

[118] G. Zhang, S. Xu, and Y. Shi, "Electromechanical coupling of lead zirconate titanate nanofibres," Micro \& Nano Letters, vol. 6, no. 1, pp. 59-61, 2011.

[119] A. Fujishima and K. Honda, "Electrochemical photolysis of water at a semiconductor electrode," Nature, vol. 238, no. 5358, pp. 37-38, 1972.

[120] N. Ghows and M. H. Entezari, "Sono-synthesis of core-shell nanocrystal $\left(\mathrm{CdS} / \mathrm{TiO}_{2}\right)$ without surfactant," Ultrasonics Sonochemistry, vol. 19, no. 5, pp. 1070-1078, 2012.

[121] R. S. Khnayzer, L. B. Thompson, M. Zamkov et al., "Photocatalytic hydrogen production at titania-supported Pt nanoclusters that are derived from surface-anchored molecular precursors," The Journal of Physical Chemistry C, vol.116, no. 1, pp. 1429-1438, 2012.

[122] S. K. Choi, S. Kim, S. K. Lim, and H. Park, "Photocatalytic comparison of $\mathrm{TiO}_{2}$ nanoparticles and electrospun $\mathrm{TiO}_{2}$ nanofibers: Effects of mesoporosity and interparticle charge transfer," Journal of Physical Chemistry C, vol.114, no. 39, pp.16475-16480, 2010. 
[123] R. Zhang, H. Wu, D. Lin, and W. Pan, "Preparation of necklacestructured $\mathrm{TiO}_{2} / \mathrm{SnO}_{2}$ hybrid nanofibers and their photocatalytic activity," Journal of the American Ceramic Society, vol. 92, no. 10, pp. 2463-2466, 2009.

[124] X. Xu, G. Yang, J. Liang et al., "Fabrication of one-dimensional heterostructured $\mathrm{TiO}_{2} @ \mathrm{SnO}_{2}$ with enhanced photocatalytic activity," Journal of Materials Chemistry A, vol. 2, no. 1, pp. 116122, 2014.

[125] S. S. Lee, H. Bai, Z. Liu, and D. D. Sun, "Optimization and an insightful properties-activity study of electrospun $\mathrm{TiO}_{2} / \mathrm{CuO}$ composite nanofibers for efficient photocatalytic $\mathrm{H}_{2}$ generation," Applied Catalysis B, vol. 140-141, pp. 68-81, 2013.

[126] F.-X. Xiao, "Construction of highly ordered $\mathrm{ZnO}-\mathrm{TiO}_{2}$ nanotube arrays ( $\mathrm{ZnO} / \mathrm{TNTs})$ heterostructure for photocatalytic application," ACS Applied Materials and Interfaces, vol. 4, no. 12, pp. 7055-7063, 2012.

[127] Y. Wang, Y. R. Su, L. Qiao et al., "Synthesis of one-dimensional $\mathrm{TiO}_{2} / \mathrm{V}_{2} \mathrm{O}_{5}$ branched heterostructures and their visible light photocatalytic activity towards Rhodamine B," Nanotechnology, vol. 22, no. 22, Article ID 225702, 2011.

[128] Y. Tong, X. Lu, W. Sun, G. Nie, L. Yang, and C. Wang, "Electrospun polyacrylonitrile nanofibers supported $\mathrm{Ag} / \mathrm{Pd}$ nanoparticles for hydrogen generation from the hydrolysis of ammonia borane," Journal of Power Sources, vol. 261, pp. 221-226, 2014.

[129] M. Kim, A. Razzaq, Y. K. Kim, S. Kim, and S. In, "Synthesis and characterization of platinum modified $\mathrm{TiO}_{2}$-embedded carbon nanofibers for solar hydrogen generation," RSC Advances, vol. 4, no. 93, pp. 51286-51293, 2014.

[130] H. Bai, Z. Liu, and D. D. Sun, "Facile fabrication of $\mathrm{TiO}_{2} / \mathrm{SrTiO}_{3}$ composite nanofibers by electrospinning for high efficient $\mathrm{H}_{2}$ generation," Journal of the American Ceramic Society, vol. 96, no. 3, pp. 942-949, 2013.

[131] Y. Liu, L. Zhao, M. Li, and L. Guo, " $\mathrm{TiO}_{2} / \mathrm{CdSe}$ core-shell nanofiber film for photoelectrochemical hydrogen generation," Nanoscale, vol. 6, no. 13, pp. 7397-7404, 2014.

[132] L. Mai, L. Xu, C. Han et al., "Electrospun ultralong hierarchical vanadium oxide nanowires with high performance for lithium ion batteries," Nano Letters, vol. 10, no. 11, pp. 4750-4755, 2010.

[133] Y. L. Cheah, N. Gupta, S. S. Pramana, V. Aravindan, G. Wee, and M. Srinivasan, "Morphology, structure and electrochemical properties of single phase electrospun vanadium pentoxide nanofibers for lithium ion batteries," Journal of Power Sources, vol. 196, no. 15, pp. 6465-6472, 2011.

[134] O. Toprakci, L. Ji, Z. Lin, H. A. K. Toprakci, and X. Zhang, "Fabrication and electrochemical characteristics of electrospun $\mathrm{LiFePO}_{4} /$ carbon composite fibers for lithium-ion batteries," Journal of Power Sources, vol. 196, no. 18, pp. 7692-7699, 2011.

[135] C. Zhu, Y. Yu, L. Gu, K. Weichert, and J. Maier, "Electrospinning of highly electroactive carbon-coated single-crystalline $\mathrm{LiFePO}_{4}$ nanowires," Angewandte Chemie-International Edition, vol. 50, no. 28, pp. 6278-6282, 2011.

[136] C. Kim, K. S. Yang, M. Kojima et al., "Fabrication of electrospinning-derived carbon nanofiber webs for the anode material of lithium-ion secondary batteries," Advanced Functional Materials, vol. 16, no. 18, pp. 2393-2397, 2006.

[137] H. S. Choi, J. G. Lee, H. Y. Lee, S. W. Kim, and C. R. Park, "Effects of surrounding confinements of Si nanoparticles on Si-based anode performance for lithium ion batteries," Electrochimica Acta, vol. 56, no. 2, pp. 790-796, 2010.
[138] Y. Yu, Q. Yang, D. Teng, X. Yang, and S. Ryu, "Reticular Sn nanoparticle-dispersed PAN-based carbon nanofibers for anode material in rechargeable lithium-ion batteries," Electrochemistry Communications, vol. 12, no. 9, pp. 1187-1190, 2010.

[139] Z. Lin, L. Ji, M. D. Woodroof, and X. Zhang, "Electrodeposited $\mathrm{MnO}_{x} /$ carbon nanofiber composites for use as anode materials in rechargeable lithium-ion batteries," Journal of Power Sources, vol. 195, no. 15, pp. 5025-5031, 2010.

[140] L. Li, S. Peng, Y. Cheah et al., "Electrospun hierarchical $\mathrm{CaCo}_{2} \mathrm{O}_{4}$ nanofibers with excellent lithium storage properties," Chemistry-A European Journal, vol. 19, no. 44, pp. 1482314830, 2013.

[141] H. Lee, M. Alcoutlabi, J. V. Watson, and X. Zhang, "Electrospun nanofiber-coated separator membranes for lithium-ion rechargeable batteries," Journal of Applied Polymer Science, vol. 129, no. 4, pp. 1939-1951, 2013.

[142] Y. Liang, S. Cheng, J. Zhao et al., "Heat treatment of electrospun Polyvinylidene fluoride fibrous membrane separators for rechargeable lithium-ion batteries," Journal of Power Sources, vol. 240, pp. 204-211, 2013.

[143] S. Jayaraman, V. Aravindan, P. S. Kumar, W. C. Ling, S. Ramakrishna, and S. Madhavi, "Exceptional performance of $\mathrm{TiNb}_{2} \mathrm{O}_{7}$ anode in all one-dimensional architecture by electrospinning," ACS Applied Materials \& Interfaces, vol. 6, no. 11, pp. 8660-8666, 2014.

[144] M. Yanilmaz, M. Dirican, and X. Zhang, "Evaluation of electrospun $\mathrm{SiO}_{2}$ /nylon 6,6 nanofiber membranes as a thermallystable separator for lithium-ion batteries," Electrochimica Acta, vol. 133, pp. 501-508, 2014.

[145] C. Kim, B. T. N. Ngoc, K. S. Yang et al., "Self-sustained thin Webs consisting of porous carbon nanofibers for supercapacitors via the electrospinning of polyacrylonitrile solutions containing zinc chloride," Advanced Materials, vol. 19, no. 17, pp. 2341-2346, 2007.

[146] E. Han, D. Wu, S. Qi et al., "Incorporation of silver nanoparticles into the bulk of the electrospun ultrafine polyimide nanofibers via a direct ion exchange self-metallization process," ACS Applied Materials and Interfaces, vol. 4, no. 5, pp. 2583-2590, 2012.

[147] J. Li, E.-H. Liu, W. Li, X.-Y. Meng, and S.-T. Tan, "Nickel/carbon nanofibers composite electrodes as supercapacitors prepared by electrospinning," Journal of Alloys and Compounds, vol. 478, no. 1-2, pp. 371-374, 2009.

[148] G.-H. An and H.-J. Ahn, "Activated porous carbon nanofibers using Sn segregation for high-performance electrochemical capacitors," Carbon, vol. 65, pp. 87-96, 2013.

[149] S.-H. Choi, T.-S. Hyun, H. Lee, S.-Y. Jang, S.-G. Oh, and I.-D. Kim, "Facile synthesis of highly conductive platinum nanofiber mats as conducting core for high rate redox supercapacitor," Electrochemical and Solid-State Letters, vol. 13, no. 6, pp. A65A68, 2010.

[150] J.-B. Lee, S.-Y. Jeong, W.-J. Moon, T.-Y. Seong, and H.-J. Ahn, "Preparation and characterization of electro-spun $\mathrm{RuO}_{2}-\mathrm{Ag}_{2} \mathrm{O}$ composite nanowires for electrochemical capacitors," Journal of Alloys and Compounds, vol. 509, no. 11, pp. 4336-4340, 2011.

[151] S. Chaudhari, Y. Sharma, P. S. Archana et al., "Electrospun polyaniline nanofibers web electrodes for supercapacitors," Journal of Applied Polymer Science, vol. 129, no. 4, pp. 1660-1668, 2013. 
[152] A. D. Lucking, L. Pan, D. L. Narayanan, and C. E. B. Clifford, "Effect of expanded graphite lattice in exfoliated graphite nanofibers on hydrogen storage," Journal of Physical Chemistry B, vol. 109, no. 26, pp. 12710-12717, 2005.

[153] Z. Kurban, Electrospun nanostructured composite fibres for hydrogen storage applications [Doctoral thesis], Department of Physics and Astronomy University College, London, UK, 2011.

[154] P. E. de Jongh and P. Adelhelm, "Nanosizing and nanoconfinement: new strategies towards meeting hydrogen storage goals," ChemSusChem, vol. 3, no. 12, pp. 1332-1348, 2010.

[155] M. Fichtner, "Nanoconfinement effects in energy storage materials," Physical Chemistry Chemical Physics, vol. 13, no. 48, pp. 21186-21195, 2011.

[156] T. K. Nielsen, F. Besenbacher, and T. R. Jensen, "Nanoconfined hydrides for energy storage," Nanoscale, vol. 3, pp. 2086-2098, 2011.

[157] G. Xia, D. Li, X. Chen et al., "Carbon-coated $\mathrm{Li}_{3} \mathrm{~N}$ nanofibers for advanced hydrogen storage," Advanced Materials, vol. 25, no. 43, pp. 6238-6244, 2013.

[158] J. Alipour, A. M. Shoushtari, and A. Kaflou, "Electrospun PMMA/AB nanofiber composites for hydrogen storage applications," e-Polymers, vol. 14, no. 5, pp. 305-311, 2014. 

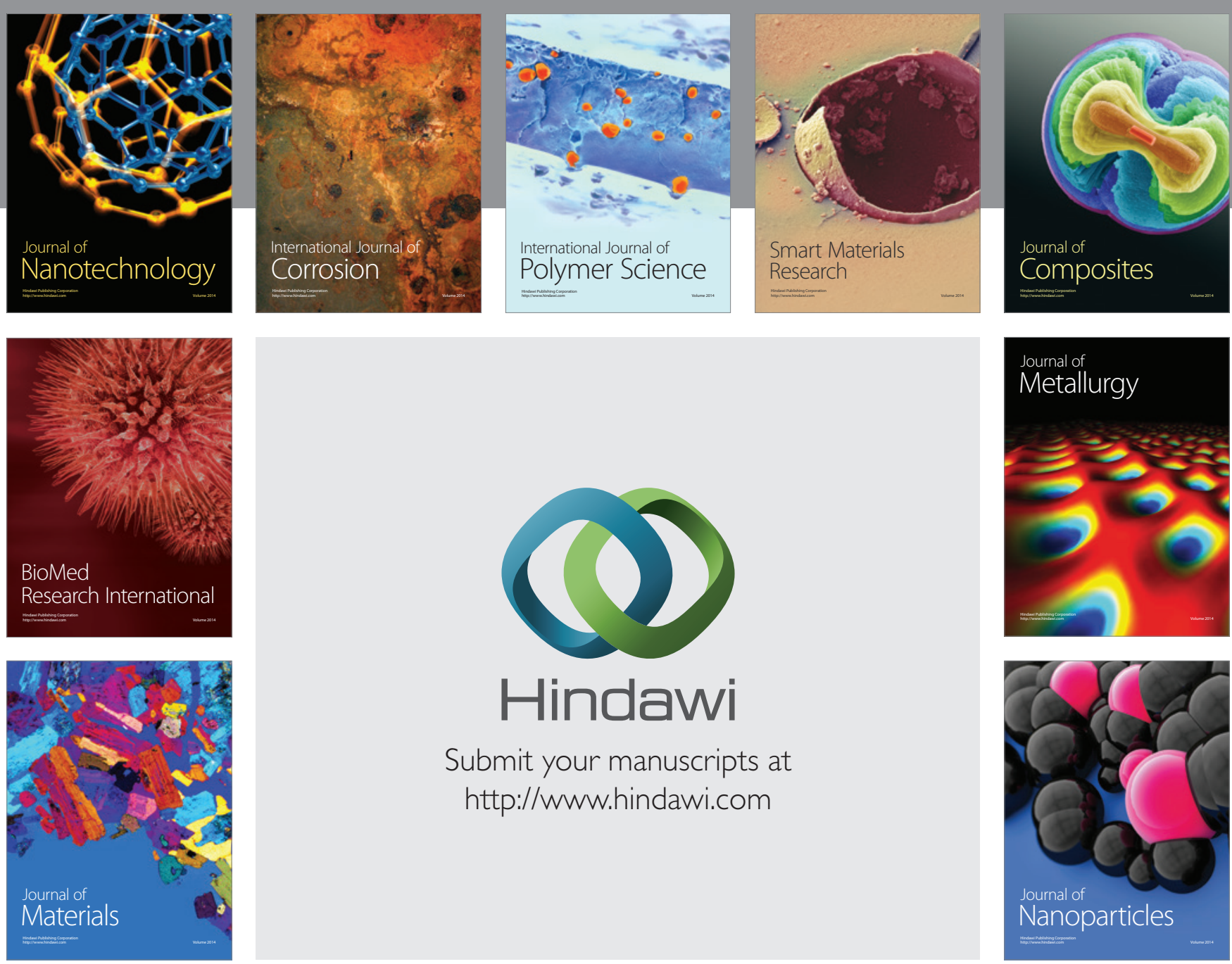

Submit your manuscripts at http://www.hindawi.com
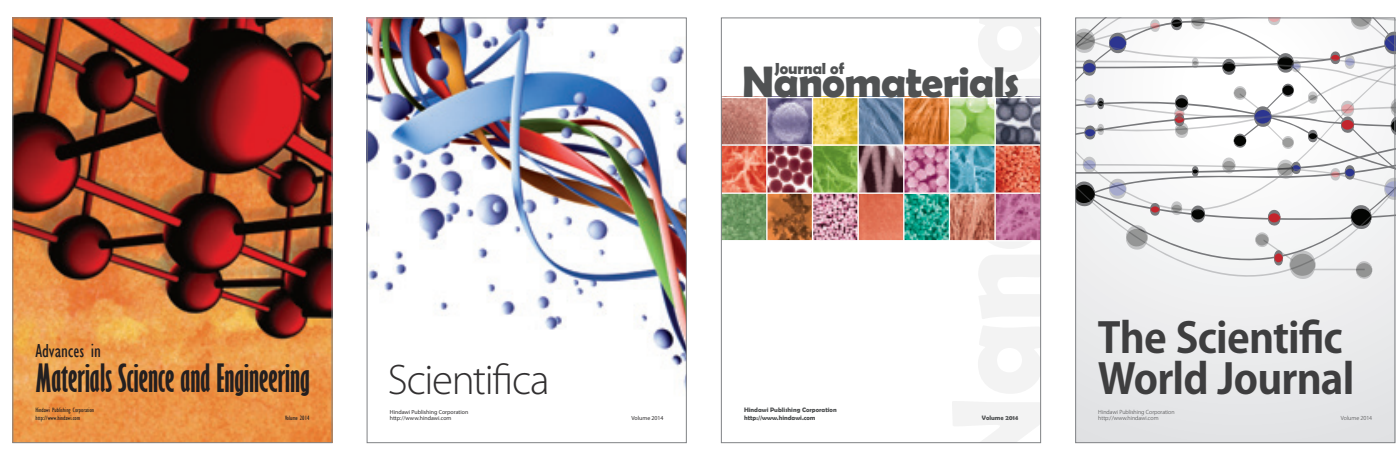

\section{The Scientific World Journal}
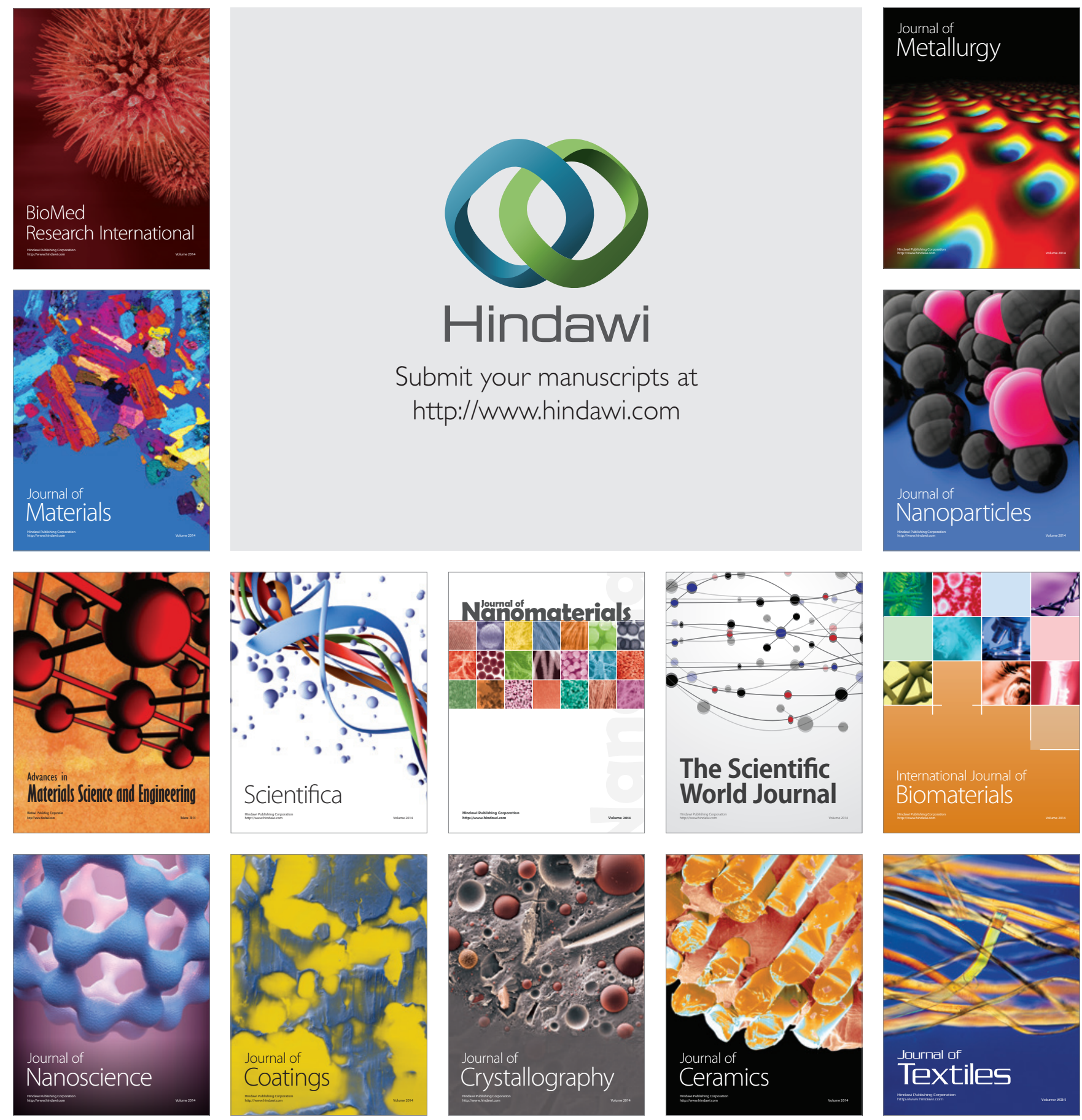